\title{
c4c: Paediatric pharmacovigilance: Methodological considerations in research and development of medicines for children - A c4c expert group white paper
}

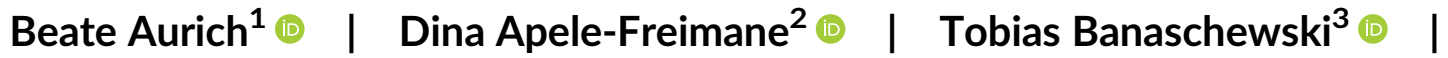 \\ Laurent Chouchana $^{4}$ (i) | Simon Day ${ }^{5}$ | Florentia Kaguelidou ${ }^{6}$ | Lauren E. Kelly ${ }^{7}$ ( ) | \\ Jenny M. Kindblom ${ }^{8}$ (i) | Antje Neubert ${ }^{9}$ @ | Ian C. K. Wong ${ }^{10,11}$ \\ ${ }^{1}$ Department of Pharmacology, Saint-Louis Hospital, Paris, France \\ ${ }^{2}$ Neonatal Intensive Care, Women and Child Health Clinic, Pauls Stradins Clinical University Hospital, Riga, Latvia \\ ${ }^{3}$ Department of Child and Adolescent Psychiatry, Central Institute of Mental Health, Medical Faculty Mannheim, University of Heidelberg, Mannheim, Germany \\ ${ }^{4}$ Regional Center of Pharmacovigilance, Department of Pharmacology, Cochin Hospital, APHP, Centre, Université de Paris, Paris, France \\ ${ }^{5}$ Clinical Trials Consulting and Training Limited, North Marston, UK \\ ${ }^{6}$ Department of Pediatric Pharmacology and Pharmacogenetics, APHP, Robert Debré Hospital; Center of Clinical Investigations, INSERM CIC1426, Université de \\ Paris, Paris, France \\ ${ }^{7}$ Department of Paediatrics and Child Health, Max Rady College of Medicine, University of Manitoba, Winnipeg, Canada \\ ${ }^{8}$ Paediatric Clinical Research Center, Queen Silvia Children's Hospital, Sahlgrenska University Hospital, Gothenburg, Sweden \\ ${ }^{9}$ Department of Paediatrics and Adolescent Medicine, University Hospital Erlangen, Friedrich-Alexander University Erlangen-Nürnberg (FAU), Erlangen, Germany \\ ${ }^{10}$ Centre for Safe Medication Practice and Research, Department of Pharmacology and Pharmacy, Li Ka Shing Faculty of Medicine, The University of Hong Kong, \\ China \\ ${ }^{11}$ Research Department of Practice and Policy, School of Pharmacy, UCL, London, UK
}

\section{Correspondence}

Beate Aurich, Department of Pharmacology,

Saint-Louis Hospital. Paris, France.

Email: beate.aurich@gmx.fr
Children frequently respond differently to therapies compared to adults. Differences also exist between paediatric age groups for pharmacokinetics and pharmacodynamics in both efficacy and safety. Paediatric pharmacovigilance requires an understanding of the unique aspects of children with regard to, for example, drug response, growth and development, clinical presentation of adverse drug reactions (ADRs), how they can be detected and population-specific factors (e.g., more frequent use of offlabel/unlicensed drugs). In recognition of these challenges, a group of experts has been formed in the context of the conect4children $(\mathrm{c} 4 \mathrm{c})$ project to support paediatric drug development. This expert group collaborated to develop methodological considerations for paediatric drug safety and pharmacovigilance throughout the life-cycle of medicinal products which are described in this article.

These considerations include practical points to consider for the development of the paediatric section of the risk management plan (RMP), safety in paediatric protocol development, safety data collection and analysis. Furthermore, they describe the 
specific details of post-marketing pharmacovigilance in children using, for example, spontaneous reports, electronic health care records, registries and record-linkage, as well as the use of paediatric pharmacoepidemiology studies for risk characterisation. Next the details of the assessment of benefit-risk and challenges related to medicinal product formulation in the context of a Paediatric Investigation Plan (PIP) are presented. Finally, practical issues in paediatric signal detection and evaluation are included.

This paper provides practical points to consider for paediatric pharmacovigilance throughout the life-cycle of medicinal products for RMPs, protocol development, safety data collection and analysis and PIPs.

\section{KEYWORDS}

adverse drug reaction, benefit-risk assessment, clinical trial protocol, paediatric, paediatric investigation plan, pharmacovigilance, risk management, safety specification, signal detection

\section{1 | INTRODUCTION}

Pharmacovigilance is defined by the World Health Organisation (WHO) as "the science and activities relating to the detection, assessment, understanding and prevention of adverse effects or any other drug-related problems". ${ }^{1}$ It is conducted throughout the life cycle of medicinal products, starting with the first administration in humans and usually ending when the product is no longer marketed in any country. ${ }^{2,3}$ Pharmacovigilance is performed on safety data originating from many different sources and countries. ${ }^{3}$ It includes a continuous evaluation of all available, global data (i.e., non-clinical and clinical data, including solicited and spontaneous reports). In addition, data for special patient populations is evaluated (e.g., patients with hepatic or renal impairment, pregnant women, children and the elderly). ${ }^{3}$ Pharmacovigilance monitors case-level and population-level data to detect and analyse treatment-related risks. The term risk includes any treatment-related safety issues such as adverse drug reactions (ADRs), interactions, medication errors, lack of efficacy, reactions to excipients, lack of compliance, device issues where relevant or any other concern related to the use of medications. ${ }^{2,3}$

Pharmacovigilance aims to improve the understanding of known (i.e., identified) and potential risks and collect any missing or incomplete safety data (e.g., risk factors for identified risks; further safety data on potential risks). Identified risks are managed through a variety of risk minimisation activities. Pharmacoepidemiology studies can help to assess these risks and the effectiveness of risk minimisation measures. ${ }^{2,4}$ The aim of paediatric pharmacovigilance is to reduce harms, optimise paediatric pharmacotherapy and provide parents and prescribers with accurate descriptions of the benefit-risk balance of available treatment options, including potential long-term effects.

The purpose of this article is to provide an introduction to paediatric pharmacovigilance and provide practical examples of paediatric pharmacovigilance and how it differs from pharmacovigilance for adults.

\subsection{Historical background of paediatric pharmacovigilance}

It is well known that in terms of drug therapy, children are not small adults. In the past, children were rather often subject to serious harms caused by drugs which led to specific measures to improve the safety of paediatric drug therapy. ${ }^{5}$ In 1938, the Food, Drug, and Cosmetic Act was signed in the United States (US) following the death of 107 patients, mainly children who had taken a new liquid form of the oral antibiotic sulphanilamide. The pharmaceutical company had intended to manufacture a special liquid formulation and used diethylene glycol as excipient to obtain an acceptable taste. However, its toxicity, which led to metabolic acidosis, was not taken into account. $^{5-7}$

A few decades later, in the late 1960s, the use of thalidomide during pregnancy led to babies being born with malformed limbs. In the U.S., this led to the Kefauver Harris Amendment to the Food, Drug, and Cosmetic Act and consequently the establishment of global pharmacovigilance. ${ }^{8}$ Following this, laws were introduced all over the world to ensure that drugs were being rigorously tested with regard to quality, efficacy and safety before being introduced to the market (licensing). Although clinical trials became mandatory before marketing approvals, the unintended consequence of these new drug safety legislations was that pharmaceutical companies generally did not conduct clinical trials in children even for treatments clearly indicated for paediatric conditions. Harry Shirkey coined the term "The Therapeutic Orphan" for this paradoxical situation. ${ }^{9}$ Research with minors was often deemed unethical and there was strong public opinion that children should not be included in clinical trials. Therefore, many drugs used in children have not been tested with regard to efficacy and safety in the paediatric population, and thus are being used offlabel. ${ }^{10}$

In the late 1990s, first initiatives in the US aimed to improve the availability of medicines for children. In Europe, the European Clinical Trials Directive, which came into force in 2001, included provisions 
for vulnerable populations, including children, allowing their inclusion into clinical trials. This was followed by the European Union (EU) Initiative Better Medicines for Children, and the Best Pharmaceuticals for Children Act in the US in 2002. In 2007, the European Paediatric Regulation came into force comprising various measures of which the conduct of paediatric clinical trials for newly marketed drugs is the most important. ${ }^{11,12}$ Notably the paediatric regulation applies to all medicinal products including those in development, patent protected and off-patent products (i.e., generics) needed for treating children.

The introduction of these laws in Europe and the US led to an increasing number of clinical trials in children, particularly with respect to newly licensed medicines. ${ }^{13}$ In Europe pharmaceutical companies are obliged to present a Paediatric Investigation Plan (PIP) before a new drug is licensed for the adult population and, where applicable, present a scientific rationale for not conducting clinical trials in children. ${ }^{14}$

While a mandate and incentives for paediatric trials has seen progress, PIPs are mandatory for any new medicines and for offpatent medicines in the context of a paediatric-use marketing authorisation (PUMA) application. However, off-patent medicines that have been on the market for a long time have limited incentives and no obligations to study these drugs in children. The uneven application of these laws across paediatric patient populations is a challenge and neonates are particularly disadvantaged..$^{15}$ In addition, in the US the regulations specify that children should only be included in clinical trials if the treatment-related risks are outweighed by the "prospect of direct benefit" to the child and that the study drug has the same or a more favourable benefit-risk balance as other treatment options. However, the lack of paediatric data makes it difficult to provide robust assessments. ${ }^{16}$ It is therefore even more important to use alternative methods to monitor drug safety. ${ }^{17}$ Along with the Paediatric Regulation, the European Medicines Agency (EMA) published a paediatric pharmacovigilance guidance, initially in 2006 , which now is included in the Good Pharmacovigilance guidance of the EMA in the section for special populations. ${ }^{18}$ Today all European member states and marketing authorisation holders operating or running trials in the EU are obliged to report their ADRs to the European EudraVigilance database. ${ }^{19}$ Other large databases include, for example, those maintained by the US Food and Drug Administration (FDA)-the FDA Adverse Event Reporting System (FAERS)-and the WHO (VigiBase). ${ }^{20,21}$ All three databases include paediatric ADR reports. $^{21-23}$

\section{2 | Differences in adverse drug reactions between children and adults}

The response of children to medication differs not only in comparison to adults but also between different paediatric age groups (e.g., neonates and adolescents). ${ }^{7,18}$ For example, premature neonates are unable to effectively metabolise and excrete chloramphenicol leading to toxic plasma levels and a clinical picture described as "grey-baby syndrome". ${ }^{24}$ Child-specific factors, including frequent off-label/unlicensed co-medications, limited pharmacokinetic (PK) and/or pharmacodynamic (PD) data, developmental differences in PK and PD, considerable variation in dose and frequency of administration due to a lack of paediatric $\mathrm{PK}$ data and a heightened risk of medication errors, may modify the risk of ADRs. ${ }^{7,18,25-27}$ Modelling and simulation can be used to support dose selection for paediatric studies and include existing safety data. ${ }^{28,29}$ Medication errors in children may or may not lead to adverse drug reactions, depending on the type of error. The reasons for these are often multifactorial, including a lack of child-friendly formulations and insufficient training of health care professionals. ${ }^{30,31}$ Furthermore, children's response to excipients may differ from adults and vary depending on the paediatric age group (e.g., alcohol should be avoided in neonatal drug formulations). ${ }^{32,33}$ Pharmacogenetic risk factors may present at different times throughout childhood and the overlapping developmental changes may lead to a similar clinical picture in children with different genotypes. ${ }^{34}$ Viral infections are more common in children (e.g., upper respiratory tract). ${ }^{35}$ Viruses may interfere with drug metabolism or modify the response of the immune system to certain medications and thereby cause an ADR. ${ }^{36-38}$ The aetiology and treatment of paediatric diseases is different compared to adults and may vary between paediatric age groups (e.g., hypertension, epilepsy) and some diseases only affect children (e.g., retinopathy of prematurity, bronchopulmonary dysplasia). ${ }^{39,40}$ These differences influence risk factors and confounders for paediatric ADRs. In neonates and infants, PK and/or PD may change rapidly during the first few months of life due to organ maturation and changes in fat disposition and enzyme activity involved in drug metabolism. ${ }^{7}$ For example, infants and young children may be at a higher risk of valproateinduced hepatotoxicity. ${ }^{7,41}$ During puberty, hormonal changes may alter drug metabolism and response. ${ }^{7,42}$ Poor adherence and concomitant use of recreational drugs can be a risk factor for ADRs in adolescents. ${ }^{43,44}$

Risks related to interactions with co-medications may differ because children may be treated with different types of co-medications. ${ }^{45,46}$ Long-term effects, for example on academic performance, fertility and growth, are a particular concern in children. ${ }^{18}$ It can be difficult to discern drug-related effects from those resulting from the underlying disease (e.g., epilepsy). Finally, risks related to pregnancy (maternal disease and in utero drug exposure) and intergenerational effects warrant consideration, in particular in the early neonatal period and infancy. ${ }^{47-52}$

The identification of paediatric ADRs requires awareness of health care professionals (HCPs), parents and pharmacovigilance experts. ${ }^{17}$ Challenges in the detection of paediatric ADRs include the need to stratify data by age group leading to small numbers in subgroups. ${ }^{53-55}$ The lack of harmonised biochemical and haematological reference values and differences in diagnostic criteria and treatment protocols between different HCPs, hospitals and countries make the analysis of multi-centre and/or multinational paediatric safety data challenging. ${ }^{26,56-58}$ Furthermore, physical examination and testing cannot be done the same way as in adults 
(e.g., neurological examinations of infants will not use the same techniques as those used in adults). Another particular challenge is that young children are not able to communicate in the same ways as adults. ${ }^{56,57,59}$ For example, an infant with hallucinations may be irritable but might not be able to accurately verbalise his/her symptoms.

\section{3 | Expertise of the $c 4 c$ pharmacovigilance expert group}

The conect4children (c4c) pharmacovigilance expert group includes a broad range of expertise including neonatology and general paediatrics, paediatric pharmacology, pharmacovigilance and pharmacoepidemiology. Some experts have worked in both the pharmaceutical industry and academic institutions. Professional experiences include working with large electronic health records (EHR) and safety databases as well as Individual Case Safety Report (ICSR) review and case series, risk management and risk minimisation, signal detection and evaluation, causality assessment, conducting pharmacoepidemiological studies, reviewing paediatric protocols and PIPs, writing safety data analysis plans, and working with Data Safety Monitoring Boards (DSMB).

\section{2 | METHODOLOGICAL AND PRACTICAL CONSIDERATIONS FOR PAEDIATRIC PHARMACOVIGILANCE}

Paediatric drug safety activities include the description of the paediatric safety specification which is the basis for the development of paediatric pharmacovigilance and risk minimisation activities in clinical practice and clinical studies. ${ }^{2,18,60,61}$ Figure 1 provides an overview of the relationship between the paediatric safety specification and paediatric pharmacovigilance and risk minimisation. The paediatric specifics of these will be presented in the following.

\subsection{Paediatric safety specification}

The paediatric safety specification (or safety profile) includes a description of the current understanding of identified and potential risks, and, where applicable, any missing information for these (e.g., risk factors, severity, outcome). It is based on the overall safety specification of the study drug which includes safety data from nonclinical studies, clinical trials, observational studies and spontaneous reports in adults and all paediatric age groups, PK and PD data, class effects and a systematic review of the safety literature including
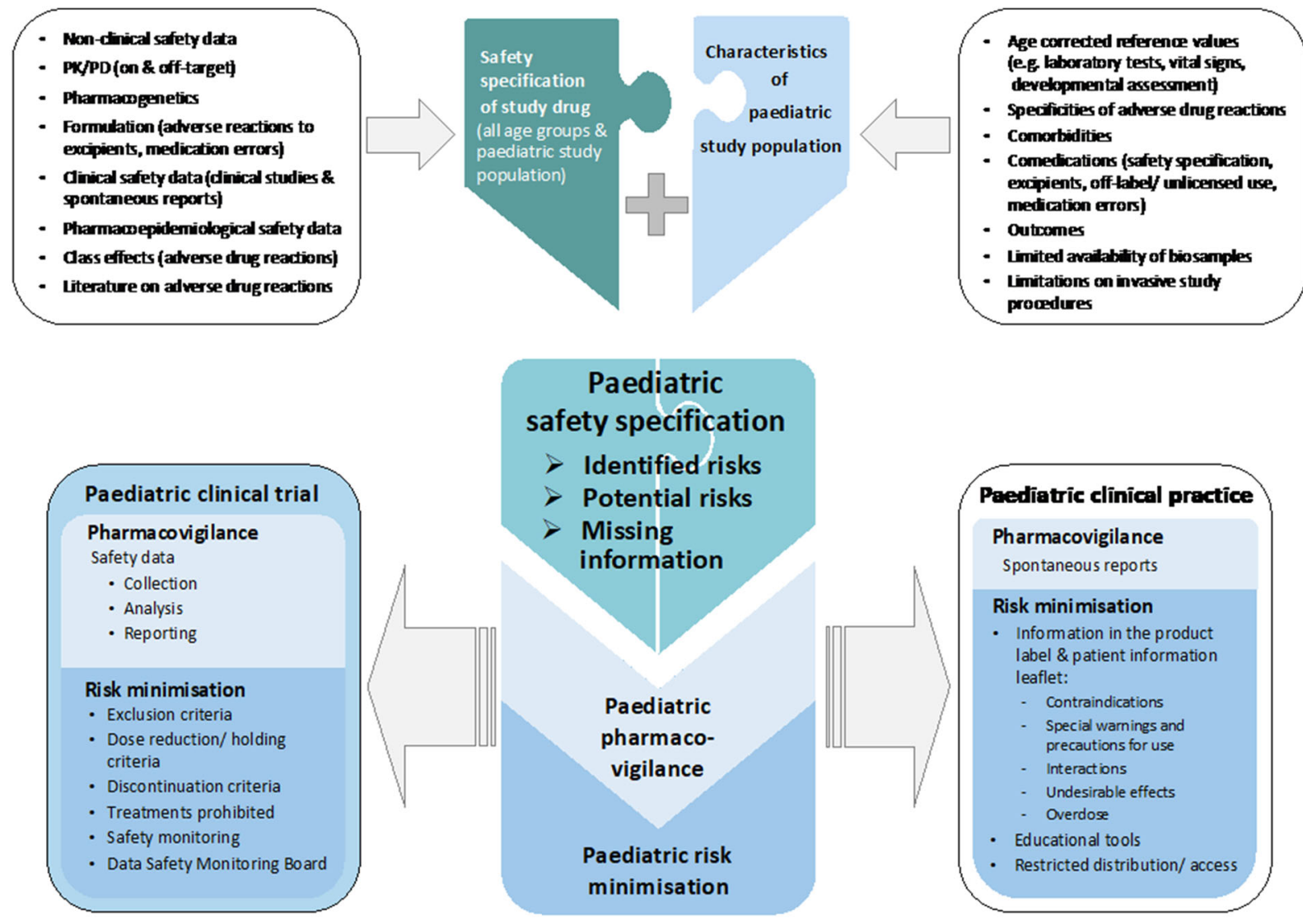

FIGURE 1 Relationship between paediatric safety specification, pharmacovigilance and risk minimisation in paediatric studies and clinical. PK, Pharmacokinetics; PD, PHarmacodynamics; ADR, Adverse drug reaction 
information from health authorities. ${ }^{2,3,18}$ This is complemented by the characteristics of the paediatric study population including, for example, the specifics of how ADRs present in children, comorbidities, comedication and age-corrected reference values ${ }^{18,62}$ (see Figure 1). Particular attention is paid to potential long-term effects. ${ }^{18,62}$

The paediatric safety specification also provides valuable information for the PIP (e.g., informing the benefit-risk balance or highlighting any issues with formulation development) which is discussed below. ${ }^{14,18,62}$ Table 1 lists some of the child-specific points that should be considered in the development of a paediatric safety specification.

\subsection{Paediatric risk management and risk minimisation}

Paediatric risk management concerns the prevention and minimisation of treatment-related risks in children and the assessment of their effectiveness.

In the EU, paediatric risk management activities are a subsection of the overall EU Risk Management Plan (RMP). 2,18,60,61 Because not all sponsors of paediatric studies will need to have an EU RMP, we will here, for the purpose of clarity, refer to paediatric risk management activities. These apply regardless of the presence or absence of an EU RMP.

The development of paediatric risk management activities is based on the paediatric safety specification. ${ }^{3,18,60}$ The aim is to reduce the frequency and/or severity of known risks and to describe how any missing safety data will be collected or studied (e.g., risk factors and outcome for identified risk and additional data on potential risks). For each risk, a description of the risk and the corresponding risk minimisation activities are included. In addition, a plan for the assessment of the effectiveness of risk minimisation activities will be presented. ${ }^{2,3,18}$ Thus a document describing paediatric risk management activities includes a summary of

- identified risks in children

- potential risks in children

- missing information (i.e., for identified or potential risks) in children.

This supports a consistent approach to the development of safetyrelated protocol sections including data collection and analysis across all protocols. Identified risks are those where there is a reasonable certainty that an adverse event (AE) is caused by a treatment. ${ }^{18,60}$ This assessment is generally based on multiple data sources and individual case reports. ${ }^{2,63,64}$ More details on the causality assessment are provided in Section 2.7.2. Potential risks are those where there is some data (e.g., preclinical data) suggesting a new ADR but the information is insufficient to ascertain causality with reasonable confidence. This may include questions about long-term risks and/or risks observed in other patient populations which may not present the same way in children or may not develop at all in paediatric patients. ${ }^{18}$ Potential risks require, by their very nature, further data collection in order to determine whether or not they are risks. Missing information may, for example, relate to questions about the frequency and severity of identified risks in children or further data required for the evaluation of potential risks. ${ }^{18,60}$

Paediatric risk minimisation activities for identified risks may range from the standard activity of communication in relevant documents such as the product label and the protocol to, for example, contraindications and exclusion criteria. ${ }^{18,60}$ Other risk minimisation activities may include testing for risk factors (e.g., genetic tests or renal function), therapeutic drug monitoring and assessing patients for early signs of known risks (e.g., hepatotoxicity). ${ }^{65-67}$ If risk minimisation activities are dependent on test results, it is important to ensure that alert values are based on validated, population-based paediatric reference values. ${ }^{18,58,68}$ In this context it is helpful to remember that not all paediatric HCPs may have access to age-groupspecific, validated reference values and that different norms may be used in different centres or countries. ${ }^{58,68,69}$ In paediatric protocols it is therefore important to provide relevant information how this will be addressed during data collection, analysis and reporting, including data reconciliation and trial monitoring procedures. For further details, see Table S1 in the Supporting Information. It is worthwhile discussing with local clinical teams what cut-off levels they use, as these may not necessarily be the same as those provided by the local laboratory.

\section{3 | Paediatric pharmacovigilance}

Paediatric pharmacovigilance is a continuous process starting when a drug is administered to the first child for the first time. This may occur in the context of a clinical trial or in clinical practice and includes offlabel and unlicensed use. ${ }^{2,18,60}$ It compares the current understanding of treatment-related risks in children (i.e., the current paediatric safety specification) with new information from clinical trials, spontaneous reports, non-clinical safety studies and observational studies. In addition, it evaluates potential risks and fills knowledge gaps for missing safety information (e.g., risk factors or outcome). ${ }^{18,60}$

This is supplemented by routine paediatric pharmacovigilance topics such as long-term effects, medication errors, lack of compliance due to formulations not being age appropriate, lack of efficacy due to underdosing, adverse effects from excipients, interactions (drug-drug, drug-food and interactions between different excipients of co-medications) and, where applicable, issues with medical devices not being sufficiently adapted to children. ${ }^{18,60,62}$ In addition, standard pharmacovigilance topics such as designated medical events (DMEs), pharmacogenetics and, where appropriate, special populations (e.g., renal or hepatic impairment) are included. ${ }^{2,3,70,71}$

The paediatric safety specification and risk management activities are updated as new safety information becomes available. ${ }^{3,18}$ Such an update may require a corresponding modification of planned or ongoing study protocols, including an update of the informed consent/ assent form and the product label. ${ }^{61}$ Figure 2 illustrates some of the key elements of the paediatric pharmacovigilance cycle. 
TABLE 1 Examples of points to consider in the development of a paediatric safety specification

$\begin{array}{ll}\text { Item } & \text { Points to consider } \\ \text { Treatment-specific safety data } & \text { Includes all safety data (i.e., children and adults) for the study drug and any class effects } \\ \text { Non-clinical } & \text { - Are there any data suggesting developmental toxicity? } \\ & \text { - Consider juvenile animal studies }\end{array}$

Pharmacokinetic/pharmacodynamic data

- What information is available to support paediatric dose selection?

- What are potential off-target effects in children?

- If there is insufficient data for children, consider an adaptive trial design and PK/PD modelling and simulation

- Consider common co-medications in children and the risk of drug-drug interaction

- Consider the risk of drug-food interaction in children

Pharmacogenetics

Risks related to the choice of formulation

Clinical safety data (i.e., clinical trials, spontaneous reports, observational studies)

Pharmacoepidemiological data

\section{Class effects}

Literature

\section{Data specific for the paediatric target population}

Laboratory data, vital signs and other investigations

Clinical presentation of adverse drug reactions

Paediatric comorbidities

Co-medication in paediatric study population

Limitations on biosampling and study-related investigations
- Is there data suggesting pharmacogenetic risk factors in children?

- Consider available data on ontogeny of pharmacogenetics

- If there is insufficient data, consider including data collection in paediatric trial

- Consider risk of medication errors

- Where possible, aim for formulation with no or few excipients

- Assess the risk of cumulative (daily and total) excipient exposure from study drug and comedications

- Analyse pooled safety data (all age groups +/- indications)

- Stratify data by age groups and other factors (e.g., indications, dose, risk factors for ADRs)

- Explore data from large safety databases (e.g., VigiBase, EudraVigilance, FAERS)

- Is there drug utilisation data for children?

- Is there pharmacoepidemiological safety data for adults and children providing more insight into risk factors, outcome and, where applicable, the effectiveness of any risk minimisation activities?

- Consider the limitations of paediatric electronic health records and administrative databases (see Section 2.5 .3 below)

- Examine class effects for children and adults

- Review literature and information on health authority websites regarding the risks of the study medication

Includes age group specific, paediatric data relevant for the identification, management and reporting of paediatric ADRs

- Ensure age group specific, validated, population-based reference values are used

- Reference values may change for individual children during the trial, in particular in neonates and infants

- Ensure CRF alert values are adjusted for the paediatric study population

- Consider how ADRs present in the age group of the study population and how this differs from other paediatric age groups and adults

- How the clinical presentation may change as the child develops (e.g., in the context of longterm follow-up)

- Consider difference in type of biomarker for safety monitoring used between children and adults

- Describe common comorbidities in the paediatric study population which may

- be a risk factor for an ADR on study drug

- may require co-medication (including off-label/unlicensed)

- be a risk factor or confounder for a safety endpoint

- Consider differences in diagnostic criteria and treatment protocols between different study sites which may impact safety data analyses

- Consider differences to adult co-medications (e.g., type of co-medications)

- Be aware of increased risk of medication errors from the use of co-medications (including off-label/unlicensed) and what type of ADRs this may cause (e.g., accidental overdose, lack of efficacy)

- Examine paediatric safety specification of co-medications and how this may influence safety data for the study drug

- Consider risks, interactions and/or additive effect of excipients of co-medications

- Where possible, consider opportunistic and/or scavenged sampling (not only for PK but also for monitoring safety)

- To the extent possible, aim for using data that is routinely collected in children (disruption to children and their families should be kept to a minimum) 
TABLE 1 (Continued)

$\begin{array}{ll}\text { Item } & \text { Points to consider } \\ \text { - Guidelines on the maximum amount of blood to be drawn for study purposes may vary } & \text { depending on the region/country } \\ \text { - Putcome in children } & \text { - Consider how outcome is usually assessed in the target population } \\ \text { - Consider involving children and their families on how outcome should be examined (e.g., } & \text { what is meaningful for them and how can this be measured objectively) }\end{array}$

PK, pharmacokinetic; PD, pharmacodynamic; ADR, adverse drug reaction; FAERS, Food and Drug Administration Adverse Event Reporting System; CRF, Case Report Form.

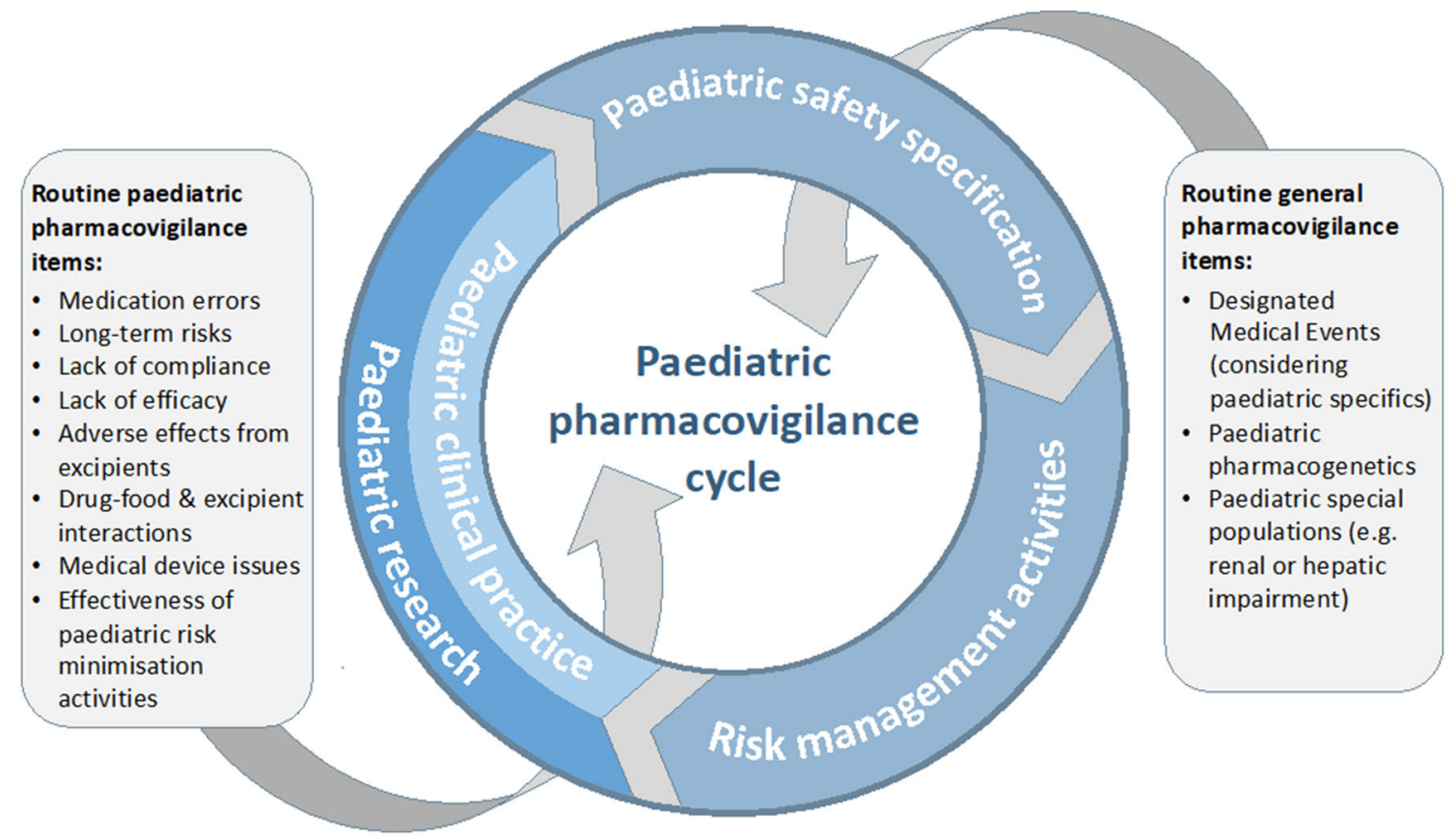

FIGURE 2 Key elements of the paediatric pharmacovigilance cycle

\subsection{Clinical studies in children: Practical points to consider for pharmacovigilance and risk management}

The paediatric safety specification and risk management activities provide the framework for collecting, analysing and reporting paediatric safety data and managing treatment-related risks. ${ }^{3,18,61}$

\subsection{1 | Protocol development}

Several protocol sections are informed by the paediatric safety specification and risk management activities., ${ }^{3,61}$ Particular attention should be paid to collecting missing or incomplete paediatric safety data such as effects on growth, fertility and psychomotor development, including academic performance. Table 2 provides practical examples of how these sections can be addressed and some of the key points from a paediatric perspective. ${ }^{72}$

\subsection{2 | Safety data collection and safety monitoring in paediatric studies}

In many paediatric studies, the collection of safety data will be opportunistic (i.e., at the time of routine clinical care) or use scavenging techniques (i.e., using the surplus of biosamples obtained during routine clinical care which would normally be discarded). ${ }^{73,74}$ The aim is to keep disruption to a minimum and to protect children from interventions which do not have any therapeutic consequences (e.g., additional physical examinations, questionnaires, imaging). It is also important to remember that there are limits on how much blood can be drawn for study purposes in children. ${ }^{62,74,75}$ The protocol needs to include clear rules about who will be taking studyrelated biosamples, how many failed attempts are permitted and what will be done if it is not possible to obtain a sample. Technical issues with obtaining good quality samples for safety monitoring need to be addressed at the time of planning a paediatric study. ${ }^{76}$ 
TAB LE 2 Practical examples of safety-related protocol sections and specific points to consider for paediatric studies

\begin{tabular}{|c|c|}
\hline Protocol section & Points to consider for paediatric protocol development \\
\hline Background information & $\begin{array}{l}\text { Consider including: } \\
\text { - Age group specific PK/PD data for study drug and excipients } \\
\text { - Non-clinical and clinical safety data (including excipients) } \\
\text { - How ADRs present in children (including risk factors and confounders) } \\
\text { - Paediatric co-medications (including excipients and medication errors) } \\
\text { - Paediatric reference ranges for safety-related data (laboratory tests, vital signs, development) } \\
\text { - Missing safety data (clinical and non-clinical, including medication errors and excipients) } \\
\text { - Benefit-risk balance in children }\end{array}$ \\
\hline Objectives & Paediatric safety should be at least a secondary objective \\
\hline $\begin{array}{l}\text { - Exclusion criteria } \\
\text { - Stopping rules } \\
\text { - Discontinuation/ } \\
\text { Withdrawal criteria }\end{array}$ & $\begin{array}{l}\text { - Based on paediatric safety specification } \\
\text { - Rules based on laboratory tests, vital signs and developmental assessments should use validated population- } \\
\text { specific reference ranges } \\
\text { - } N \text { times ULN/LLN can be used, where local laboratory testing is used instead of a central laboratory } \\
\text { - Ensure that paediatric vital signs are reviewed by a paediatric specialist (e.g., electrocardiograms) }\end{array}$ \\
\hline $\begin{array}{l}\text { Treatment(s) not } \\
\text { permitted }\end{array}$ & $\begin{array}{l}\text { - Based on drug interactions (drug-drug, drug-food) } \\
\text { - Include interactions of excipients from co-medications (i.e., excipient-excipient interaction) }\end{array}$ \\
\hline $\begin{array}{l}\text { Safety monitoring and } \\
\text { follow-up }\end{array}$ & $\begin{array}{l}\text { - Based on paediatric safety specification (including concerns about potential long-term effects, e.g. on growth, } \\
\text { psychomotor development, fertility) } \\
\text { - Consider how AEs/ADRs present in children and the effect of paediatric comorbidities (e.g., risk factors or } \\
\text { confounders for treatment emergent AEs) } \\
\text { - Consider which paediatric ADRs (including their severity/seriousness and outcome) are considered expected/ } \\
\text { listed } \\
\text { - Rules based on laboratory tests, vital signs and developmental assessments should use validated, population- } \\
\text { - } \mathrm{N} \text { times ULific refence ranges } \\
\text { - Ensure that paediatric vital signs are reviewed by a paediatric specialist (e.g., electrocardiograms) } \\
\text { - Data collection may be restricted by limitations for biosampling } \\
\text { - Invasive testing should be kept to a minimum in children, in particular where there are no therapeutic consequences } \\
\text { - Physical examinations need to be adapted to children } \\
\text { - Record co-medications in the CRF using paediatric standards (i.e., } \mathrm{mg} / \mathrm{kg} \text { ) } \\
\text { - Include data collection for missing safety information } \\
\text { - Record medication errors of the study drug and co-medications in the CRF }\end{array}$ \\
\hline Safety data analysis plan & $\begin{array}{l}\text { - Based on: } \\
\text { - paediatric safety specification } \\
\text { - missing or incomplete safety information in children } \\
\text { - Should include analyses of: } \\
\text { - risk factors in children } \\
\text {-medication errors } \\
\text { - adverse effects from excipients } \\
\text { - interactions (drug-drug, drug-food) } \\
\text { - medical devices issues (where relevant) } \\
\text { - designated medical events adapted to the paediatric study population } \\
\text { - pharmacogenetics (where applicable) } \\
\text { - children with pre-existing renal or hepatic impairment } \\
\text { - long-term effects } \\
\text { - Certain data analyses should only be done by paediatric specialists (e.g., ECGs) } \\
\text { - Sponsor and Data Safety Monitoring Board safety analyses should complement each other }\end{array}$ \\
\hline $\begin{array}{l}\text { Safety criteria for trial } \\
\text { termination }\end{array}$ & $\begin{array}{l}\text { Based on: } \\
\text { - Paediatric safety specification } \\
\text { - Benefit-risk balance in children }\end{array}$ \\
\hline
\end{tabular}

PK, pharmacokinetic; PD, pharmacodynamic; ADR, adverse drug reaction; ULN, upper limit of normal; LLN, lower limit of normal; AE, adverse event; CRF, Case Report Form; ECG, electrocardiogram; mg, milligram; kg, kilogram.

Social and cultural differences of what is acceptable in terms of intervention and different concepts of health and disease should be considered during the study design. ${ }^{77-79}$

The collection of safety data in a paediatric study is, on one side, informed by the paediatric safety specification (e.g., identified and potential risks and missing information) and, on the other side, by a more general approach of collecting AEs, regardless of severity, seriousness, expectedness or causality. ${ }^{2,3,18} \mathrm{~A}$ frequent challenge in paediatric studies is the lack of validated, age-group-specific safety endpoints. In addition, AEs which are frequently identified as ADRs, 
so-called DMEs, will be reviewed whilst considering how they would present in children. ${ }^{18,71} \mathrm{AEs}$ may include abnormal test results. If an $A E$ is reported without any test result, it might be relevant to document whether it has been reported by parents/care takers and whether the child has been reviewed by a paediatric HCP. As for adults, every effort should be made to obtain the final diagnosis which should then be added to the Case Report Form (CRF) and coding should ensure the $A E$ is coded to the diagnosis and not kept separate. ${ }^{80}$ For example, if the initial $A E$ was feeding difficulties and the final diagnosis was pneumonia, the CRF needs to be updated to ensure the symptom of feeding difficulties is coded under the term of pneumonia. From a pharmacovigilance perspective, feeding difficulties in a child can be due to a broad range of childhood diseases. It is therefore essential to follow up on AEs that are symptoms to ensure the correct diagnosis is entered in the CRF. Any AE reported in a paediatric clinical trial should include sufficient data to assess severity, outcome and causality, and, where applicable, understand risk factors and potential confounders. ${ }^{18,81}$ Details on what should be included in a paediatric ICSR are provided in Table 4 in Section 2.5.1.

Training paediatric investigators on the assessment of causality is important in order to ensure that new risks are identified as soon as possible. It is recognised that the causality assessment of paediatric ICSRs can be challenging. Therefore, it has been recommended to simplify the process by asking investigators only whether or not there is a reasonable possibility that the $A E$ is related to the study drug. ${ }^{82}$ This avoids going into more details concerning the level of certainty of a causal relationship as this does not usually contribute to the identification of new safety signals once aggregate data is reviewed. Points to consider for the assessment of the causality of paediatric ICSRs are provided in Table S2 in the Supporting Information. ${ }^{63,64,82-84}$

The assessment of severity should be adapted to the age group of the paediatric study population. The protocol should state which criteria are used and, if there are no established, published standards, the protocol should detail how severity is assessed, for example by modifying the National Institutes of Health Division AIDS (DAIDS) criteria. ${ }^{85-87}$ The evaluation of seriousness of paediatric AEs should follow standard seriousness criteria. ${ }^{81}$

It is useful to remember that the quality of ICSRs is key and will help escalate new information in a timely manner. Therefore, investigator training should include the current understanding of the paediatric safety specification and what should be included in a case report explaining why it is important. CRFs with auto-populated fields from the CRF database such as the name of the reporting investigator, the age, sex, weight, height, relevant medical history, co-medications, start date of study drug, dose and frequency will help investigators to provide all the relevant information in the initial report and reduce the number of follow-up requests from the sponsor or health authorities. $^{82,83}$

Particular attention should be paid to ensure CRFs are adapted to the paediatric study population. ${ }^{88-90}$ If a PK study is embedded into the study, the exact time of administration of the study drug and relevant co-medications which may influence study drug PK as well as the sampling time need to be correctly recorded. ${ }^{91}$ It is worthwhile discussing and agreeing with the HCP team of the study site on the most feasible way of doing so because paediatric wards can get very busy. Table 3 provides points to consider for paediatric CRFs.

\subsection{3 | Safety data analysis in paediatric studies}

The statistical analysis plan (SAP) of a paediatric study should consider how ADRs present in children. Whilst considering individual studies, where possible safety data should be pooled from all paediatric trials, and this is commonly referred to as a Programme Safety Analysis Plan (PSAP). For identified and potential risks, AEs should be grouped by relevant medical concepts, for example using Standardised Medical Dictionary for Regulatory Activities (MedDRA) Queries (SMQ), noting that not all SMQs might be appropriate for children. ${ }^{92}$ For example, if there is concern about a drug causing hallucinations, MedDRA Preferred Terms (PTs) of age-group-specific signs and symptoms should be grouped together. For a practical example, see Table S3 in the Supporting Information.

The SAP (or PSAP) should include descriptive analyses on the frequency, severity, seriousness and duration of ADRs and their outcome. Safety data analyses should also cover standard paediatric pharmacovigilance issues as described in Table 2. Test results for safety data (e.g., haematology) should be analysed in relation to the age-appropriate reference values and the number of patients with abnormally high or low values, and the severity of the abnormality should be included using common standards. ${ }^{61,82,85,86,93,94}$ In general, the emphasis of the analysis should be on estimating incidences, rather than statistical hypothesis testing. It is helpful to remember that most clinical trials, regardless of the age group, are underpowered to detect ADRs occurring in fewer than 1/1000 patients exposed. The majority of paediatric trials have a smaller sample size than adult studies, and any conclusions about treatment-related risks in children should be carefully considered.

The causality of paediatric safety data can be assessed using a structured approach such as the considerations proposed by Austin Bradford Hill.63,64,82,84 Supporting Information Table S2 provides examples of questions for the assessment of causality of paediatric ICSRs and aggregate data based on the Bradford Hill points to consider. Further details on paediatric signal evaluation are described in Section 2.7.2.

\subsection{4 | Challenges of paediatric pharmacovigilance in multi-centre and multinational studies}

For multinational paediatric trials that are not collaborating with the EMA, local pharmacovigilance regulations may need to be addressed at the time of trial conception to ensure a harmonised approach. The paediatric safety specification of the study drug and the planned risk management activities can be helpful in clarifying how for example 
TAB LE 3 Paediatric Case Reports Form design: Points to consider for safety data collection

\begin{tabular}{|c|c|}
\hline Item & Points to consider \\
\hline Age & $\begin{array}{l}\text { - Different practices may exist for how age is documented in neonates and premature infants } \\
\text { - Ensuring age is correctly documented and in a harmonised manner across study sites will facilitate the } \\
\text { efficacy and safety }\end{array}$ \\
\hline $\begin{array}{l}\text { Weight and height and } \\
\text { percentile or z-score }\end{array}$ & $\begin{array}{l}\text { - Depending on the study population and the duration of the study, weight and height may be measured } \\
\text { repeatedly } \\
\text { - Weight, height and/or age may be used to calculate the dose of the study drug and any co-medications } \\
\text { - Both measures are plotted on growth charts which may be population-specific (e.g., for premature infants or } \\
\text { children with certain conditions such as Down's syndrome) }\end{array}$ \\
\hline $\begin{array}{l}\text { Alert values for laboratory and } \\
\text { vital signs }\end{array}$ & $\begin{array}{l}\text { - Alert values should be appropriate for the age group } \\
\text { - Some reference values change as the child develops and may therefore need to be adapted during the trial; in } \\
\text { neonates these changes can occur within days }\end{array}$ \\
\hline Adverse events & $\begin{array}{l}\text { - Coding dictionaries may not include sufficient granularity to code paediatric conditions correctly } \\
\text { - Consider addressing any potential coding issues in a trial-specific coding guidance/standard operating } \\
\text { procedure } \\
\text { - Consider seeking paediatric pharmacovigilance expert advice }\end{array}$ \\
\hline Co-medication & $\begin{array}{l}\text { - Co-medications should be captured with sufficient detail including the brand name of the product, because } \\
\text { excipients may vary depending on the brand } \\
\text { - Additional information in the CRF should include whether these were extemporaneous preparations and the } \\
\text { exact dose (e.g., } \mathrm{mg} / \mathrm{kg} / \mathrm{dose} \text { ) frequency and duration of administration } \\
\text { - Medication errors and device issues for co-medications should be captured as they may be confounding } \\
\text { factors for AEs }\end{array}$ \\
\hline Medical history & $\begin{array}{l}\text { Antenatal (including in utero exposure and perinatal complications) and family history and the socio-cultural } \\
\text { context should be captured where these may be risk factors or confounders for treatment related risks and } \\
\text { overall outcome in children }\end{array}$ \\
\hline Developmental assessment & $\begin{array}{l}\text { - Should be completed at least at base-line and, depending on the duration of the study, at the time of routine } \\
\text { appointments for developmental assessments, trial completion and at the end of follow-up } \\
\text { - For multinational/multisite studies, one single method should be used where possible, ensuring that the tools } \\
\text { can be used in different cultural contexts }\end{array}$ \\
\hline
\end{tabular}

CRF, Case Report From; AE, adverse event.

serious adverse events (SAEs) will be managed. Where there are questions from the health authority (HA) or ethics committees, it may help to ask a paediatric pharmacovigilance physician to respond to these and/or to provide supporting documentation.

Data analysis of paediatric multinational or multi-centre studies needs to take into consideration how the disease of interest and common comorbidities, which might be risk factors, are diagnosed and treated at each study site. ${ }^{26,57,69}$ There are often considerable differences, for example depending on what kind of diagnostic tests and medications are available. Thus, if this cannot be harmonised at the outset of the study, data collection and analyses will need to take these differences into account by, for example, collecting additional data and stratifying data analyses. Similarly, reference values for laboratory tests, vital signs and developmental assessments may differ significantly between sites. ${ }^{68}$ If the testing method is the same (i.e., same sampling technique, delay of processing, laboratory machine and technique), a single reference value may be used, which should be based on a validated large paediatric population. ${ }^{58,68}$ Reference values derived from adults are not acceptable. Alternatively, local test results can be transformed into n-times lower limit of normal (LLN) and upper limit of normal (ULN) (e.g., $3 \times$ ULN). ${ }^{85,86}$ If local reference values are used, they should be appropriate for the paediatric age group. It might be useful to discuss with HCPs at the site how laboratory results influence patient management (i.e., what are thresholds in clinical practice). Finally, the analysis of safety data, including follow-up information, should consider adjusting for differences in the time of observation because data capture may not be harmonised across different sites and should ideally be integrated into local routine child health care practices. Time to event analyses can be helpful in such situations (e.g., counting from the first/most recent dose to when the event occurred). ${ }^{95-97}$

\section{5 | Post-marketing pharmacovigilance in children}

Post-marketing pharmacovigilance in children has changed from mainly including spontaneous reports to comprehensive pharmacovigilance. It continuously assesses the current understanding of the paediatric safety specification against any new information from non-clinical and clinical studies (interventional and observational) and spontaneous reports in all patients and children exposed to the drug of interest. ${ }^{2,3,18}$ The goal of post-marketing pharmacovigilance studies is to collect information on identified and potential risks or the effectiveness of risk minimisation activities. ${ }^{18}$ 
TAB LE 4 Examples of points to consider for paediatric case report

\begin{tabular}{|c|c|c|}
\hline Data element & Comment & Points to consider \\
\hline Age & $\begin{array}{l}\text { The way age is expressed in children } \\
\text { changes with age. It is different for } \\
\text { premature neonates, neonates born at } \\
\text { term and infants up to the age of } \\
36 \text { months completed. Thereafter age is } \\
\text { counted in years. However, for the } \\
\text { purpose of the assessment of growth, the } \\
\text { age of older children and adolescents is } \\
\text { counted in years and completed months }\end{array}$ & $\begin{array}{l}\text { Report age as appropriate for the child, i.e. } \\
\text { in completed hours, days, weeks, months, } \\
\text { years }\end{array}$ \\
\hline \multirow[t]{2}{*}{$\begin{array}{l}\text { Growth (weight, height and head } \\
\text { circumference) }\end{array}$} & $\begin{array}{l}\text { In children most drug doses are calculated } \\
\text { based on body weight or BSA +/- age }\end{array}$ & $\begin{array}{l}\text { Report current height and weight; where no } \\
\text { recent measurements are available, } \\
\text { report the age at which these were taken }\end{array}$ \\
\hline & $\begin{array}{l}\text { Growth is a sensitive indicator of overall } \\
\text { health }\end{array}$ & $\begin{array}{l}\text { Include growth history in medical history } \\
\text { section }\end{array}$ \\
\hline \multirow{2}{*}{ Suspected drug(s) and co-medications } & $\begin{array}{l}\text { Children may have been co-medicated with } \\
\text { herbal medicines and/or OTC medicines }\end{array}$ & $\begin{array}{l}\text { Information may need to be actively sought } \\
\text { from parents. }\end{array}$ \\
\hline & $\begin{array}{l}\text { In adolescents, careful enquiry about the } \\
\text { recreational use of alcohol and illicit } \\
\text { drugs should be considered where } \\
\text { applicable }\end{array}$ & $\begin{array}{l}\text { Report recreational use of alcohol or illicit } \\
\text { drugs if they are a confounding or risk } \\
\text { factor for ADRs or cause interactions }\end{array}$ \\
\hline Route of administration & $\begin{array}{l}\text { Drugs may be administered in children via } \\
\text { different routes than what is specified in } \\
\text { the product label }\end{array}$ & $\begin{array}{l}\text { Include route of administration including } \\
\text { any administration via a feeding tube }\end{array}$ \\
\hline Medication errors & $\begin{array}{l}\text { Children are at risk of medication errors. } \\
\text { Care should be taken to enquire about } \\
\text { the possibility of such an error }\end{array}$ & $\begin{array}{l}\text { Consider asking for a demonstration of how } \\
\text { the dose was prepared and then } \\
\text { administered to the child }\end{array}$ \\
\hline Laboratory tests and vital signs & $\begin{array}{l}\text { Paediatric reference values for laboratory } \\
\text { tests and vital signs can vary considerably } \\
\text { between laboratories }\end{array}$ & Include reference values \\
\hline Medical history & $\begin{array}{l}\text { Risk factors for paediatric ADRs and } \\
\text { confounding factors vary depending on } \\
\text { the age of the child and their medical } \\
\text { condition(s) }\end{array}$ & $\begin{array}{l}\text { Include any history of: } \\
\text { - developmental delay } \\
\text { - congenital/hereditary disorders } \\
\text { - relevant family history } \\
\text { - in-utero exposure } \\
\text { - complications of pregnancy and delivery } \\
\text { - exposure to environmental toxins (e.g., } \\
\text { lead) }\end{array}$ \\
\hline Adverse drug reaction & $\begin{array}{l}\text { ADRs may present differently in children } \\
\text { compared to adults }\end{array}$ & $\begin{array}{l}\text { Include: } \\
\text { - detailed description of clinical signs/ } \\
\text { symptoms } \\
\text { - results of investigations } \\
\text { - final diagnosis (where possible) }\end{array}$ \\
\hline
\end{tabular}


TABLE 4 (Continued)

\begin{tabular}{|c|c|c|}
\hline \multirow[t]{2}{*}{ Data element } & Comment & Points to consider \\
\hline & & $\begin{array}{l}\text { - any actions taken (treatments, stopping } \\
\text { the drug or dose modifications) } \\
\text { - outcome } \\
\text { - is ADR follow-up ongoing at the time of } \\
\text { reporting? }\end{array}$ \\
\hline Lack of efficacy & $\begin{array}{l}\text { For cases reporting lack of efficacy, detailed } \\
\text { information on the suspected drug and } \\
\text { co-medications should be supplemented } \\
\text { by a consideration of a possible lack of } \\
\text { compliance }\end{array}$ & $\begin{array}{l}\text { Include (where applicable): } \\
\text { - difficulties with drug administration } \\
\text { - problem with the taste of the medicine } \\
\text { - change in responsibilities of drug } \\
\text { administration (e.g., in adolescents from } \\
\text { an administration by parents to self- } \\
\text { administration) }\end{array}$ \\
\hline
\end{tabular}

BSA, body surface area; ADR, adverse drug reaction; OTC, over-the-counter; mg, milligram; kg, kilogram.

\subsection{1 | General aspects of paediatric spontaneous reports}

Whilst pharmacovigilance is part of any clinical trial, the number of children included in any given trial is usually small. This means that only very common $(\geq 10 \%)$ or common (between $\geq 1 \%$ and $<10 \%$ ) ADRs might be detected. ${ }^{98,99}$ Less frequent ADRs are often identified from spontaneous reports.

However, it is important to remember that only a very small fraction of ADRs, between $1 \%$ and $10 \%$, are reported. ${ }^{100}$ In addition, HA communications or high-profile publications can bias reporting. ${ }^{101}$ Underreporting of paediatric ADRs is, among others, influenced by fear of litigation in particular for off-label/unlicensed prescribing, which is still very common in children. ${ }^{102}$ Reporting of paediatric ADRs is different compared to adults. ${ }^{103,104}$ Paediatric ADRs can be more difficult to identify and case reports require more information compared to adults. High-quality spontaneous reports are key for identifying new paediatric safety signals. Therefore, particular attention needs to be paid to the information included in paediatric ICSRs and follow-up may help in providing a high-quality report. ${ }^{105}$ Table 4 lists examples of points to consider for paediatric case reports. ${ }^{18,81,106}$

As for adults, calculating the incidence of paediatric ADRs based on spontaneous reports is not possible, because the number of children exposed to the drug of interest is not known. In addition, efforts for the estimation of a denominator are hampered by the fact that databases recording dispensed drugs frequently code data as defined daily dose (DDD), which is the estimated daily maintenance dose for adults. ${ }^{107}$ Since children may have been prescribed a smaller or larger dose and prescribing practices vary considerably between HCPs, it is currently difficult to derive reliable numbers for children. ${ }^{26}$

For spontaneous reports, it is considered that the report implies a possible causal relationship between the reported event and treatment. ${ }^{81}$ However, regulatory authorities and pharmaceutical companies may add a comment on the case report concerning their own assessment of the case. Large databases such as EudraVigilance, VigiBase, FAERS and company databases are then used for signal detection. ${ }^{19-21}$ In these databases differences have been reported between children and adults for the type of the most commonly reported ADRs and the medications most frequently associated with these events. ${ }^{21,108,109}$ The particularities of paediatric signal detection and causality assessment are described in more detail in Section 2.7.

\subsection{2 | Paediatric post-marketing} pharmacovigilance studies (e.g., registries, case-control studies, long-term follow-up using record linkage)

Examples of post-marketing pharmacovigilance studies in paediatric medicine include the use of registries, targeted surveillance programs and linkage of clinical data with administrative data for long-term follow-up.

Registries are common in paediatrics, particularly for rare diseases where they become essential to inform disease course and evaluate potential new therapies or additional indications for existing approved medicines. Clinical datasets and patient registries provide valuable information on co-medication, medication errors, off-label indications, subgroups which may not benefit, and signals of dependence, all of which are extremely useful to identify participants for case-control studies. Case-control studies evaluate the presence of an exposure in cases (where the outcome of interest is present) and controls (where the outcome is absent). ${ }^{110}$ Case-control studies are an efficient use of resources when studying diseases with long latency which would otherwise necessitate many years of follow-up before the outcome occurs (e.g., cancer). ${ }^{110}$ Methodological considerations including the selection of a control group and details on exposure history should be established a priori so as to limit bias. ${ }^{4}$ Furthermore, management of confounding bias should acknowledge that researchers cannot control for variables for which they have no data, which often include environmental factors and social determinants of health.

Targeted surveillance programs are particularly useful for collecting detailed data about children presenting with SAEs and ADRs. Surveillance networks also provide drug developers with essential information about disease incidence, disease burden, potential drugdrug interactions, and short-term outcomes. The International Network 
of Paediatric Surveillance Units (INoPSU) was established in 1998 and includes 12 surveillance units (Australia, Belgium, Canada, Germany, Greece \& Cyprus, Ireland, New Zealand, Netherlands, Portugal, Switzerland, England and Wales), and more than 10000 clinicians caring for more than 50 million children globally. ${ }^{111}$ This collaborative effort allows studies to be undertaken simultaneously for comparison among geographical regions. ${ }^{111}$ Each individual network is responsible for collecting data and governance of their own unit. ${ }^{112}$ Paediatric surveillance units have had dramatic impacts on public health, including the development of clinical practice guidelines, health planning services, vaccine-preventable diseases and injury prevention. ${ }^{111}$

The International Association of Cancer Registries and the European Cystic Fibrosis Society are examples of disease-specific, international collaborations supporting, for example, research on disease incidence, risk factors, basic science, treatment outcome and quality of life. ${ }^{113,114}$ These registries may also get involved in postapproval safety studies (PASS) in the context of an EU RMP. ${ }^{115}$

Outside of Europe, programs such as the Canadian Paediatric Surveillance Program (CPSP) involve partnerships with government (Public Health Agency of Canada), professional societies (the Canadian Paediatric Society) and more than 1800 paediatricians and paediatric subspecialists. ${ }^{116}$ The CPSP was established to evaluate rare exposures (fewer than 500 cases per year expected), address an important public health issue of scientific importance, and fill significant knowledge gaps for which surveillance is the most appropriate means. Surveillance studies provide vital insight into clinical uses for approved medicines which can lead to revised marketing authorisations that improve patient safety and encourage access to effective therapies. Surveillance studies should be designed with clear objectives, a prespecified analysis plan, considerations for patient confidentiality, and reflect practical demands on paediatrician workload. There are limitations to both registries and surveillance networks as often the variables collected are prespecified and may not include biological samples to assess the impact of potentially relevant genomic risk factors.

\subsection{3 | Challenges of using electronic health records for paediatric safety pharmacoepidemiology studies}

Paediatric pharmacoepidemiology safety studies provide important data on the use of medications in a large number of children, help understand risk factors and outcome (short- and long-term) of ADRs and support the assessment of the effectiveness of risk minimisation activities. ${ }^{117}$ They use large electronic health record (EHR) or administrative databases or a combination of both. The benefits of linking participants include:

- minimising the effects of drop-out

- minimising research participant burden

- evaluating health care utilisation.

It can be challenging, however, to combine EHR and administrative data across jurisdictions as many privacy laws do not allow certain data to leave the region. Coding of paediatric data requires an understanding of how diseases are diagnosed and treated in children. An additional challenge is that young children and those with developmental delay may not be able to communicate effectively clinical signs of ADRs. This means that parents and health care professionals may need to interpret what the child is trying to express. It is therefore important that standard operating procedures for paediatric data are population-specific and that they have been validated. The validation of paediatric coding algorithms, diagnostic criteria and the control of data quality are recommended for all paediatric studies using EHR and administrative databases. Therefore, whilst the standards of good pharmacoepidemiology practice apply to children, understanding how paediatric data is included and coded in these databases is key. ${ }^{118-121}$ EHRs in general are not adapted for paediatric use, which in part is due to the lack of paediatric functionalities of databases originally created for adults. ${ }^{122}$ For example, in the US only $8 \%$ of paediatricians use a fully functional paediatric EHR. ${ }^{122}$ Therefore, at the time of planning a study and selecting a database, it is helpful to understand for which patient population the database was initially created and which adjustments, if any, were made to capture paediatric data. ${ }^{122,123}$ Supporting Information Table S4 lists some examples of the challenges for paediatric pharmacoepidemiology studies.

\section{6 | Paediatric Investigation Plan}

According to EU legislation, pharmaceutical companies applying for a marketing authorisation of a new drug/indication usually need to submit a PIP at the time of completing human PK studies at the latest. ${ }^{14}$ If clinical studies are planned in children, the plan will include among others a statement on benefit-risk and include considerations for the development of age-appropriate formulations. ${ }^{14}$

\subsection{1 | Benefit-risk assessment in children}

The assessment of the benefit-risk balance in children includes a transparent and structured approach weighing benefits and risks of a given treatment and then comparing it to the paediatric benefit-risk profile of other treatment options. ${ }^{62,124,125}$ This includes, for example, long-term benefits and risks and the views of children and their families on these. ${ }^{62,124-127}$ The assessment of risks for children should be based on the paediatric safety specification. Whilst the benefit-risk assessment is a mandatory section in the PIP, it is also good practice to include such an assessment in the introduction of clinical trial protocols. ${ }^{14,61}$

\subsection{2 | Formulation development and drug safety}

Medicines prescribed to children need to have a formulation adapted to the needs of children across the developmental age spectrum. ${ }^{128}$ Doses for children are usually calculated based on weight, 
which varies widely between patients and changes continuously. Therefore, it needs to be possible to administer the formulation, for example, to a premature neonate weighing just $500 \mathrm{~g}$ and an adolescent weighing $70 \mathrm{~kg}$. Polypharmacy is common in neonates and children admitted to intensive care, and off-label or unlicensed use is particularly common in these patients. ${ }^{129-132}$ This is associated with the need to manipulate the formulation, for example by crushing tablets or dilution. ${ }^{129}$ Medication errors due to drug manipulation and drug administration errors are common in children and can have serious consequences. ${ }^{133}$ Safety-related points to consider in the development of paediatric formulations are listed in Table S5 in the Supporting Information.

The metabolic capacities of children and, in particular, neonates and infants, are not the same as those in adults. ${ }^{2,7,130}$ This does not only concern the metabolism of the active moiety of a medicine but also the excipients. ${ }^{32,129,134}$ Due to developmental immaturity, excipient thresholds considered safe for adults may be harmful for children. There is currently limited data on the paediatric safety of many of the excipients included in adult medicines. ${ }^{32,129,134}$ However, several excipients, such as benzyl alcohol, are known to be unsafe. $^{32,129,134,135}$ In addition, children may be treated with several other medications which may have the same excipients as the study drug. Thus the recommended daily threshold for one or more excipients may be exceeded. ${ }^{135-137}$ Finally, interactions between different types of excipients may lead to toxicity. ${ }^{138}$ Due to the vulnerability of children, it is recommended to aim for formulations with as few excipients as possible and ideally none at all. ${ }^{129,135,139}$ The current knowledge on excipients in paediatric medicines is available from the Safety and Toxicity of Excipients for Paediatrics (STEP) database. ${ }^{140}$ Examples of safety points to consider for excipients in paediatric formulations are listed in Table S6 in the Supporting Information.

\section{7 | Advanced paediatric pharmacovigilance methods}

Advanced methods in paediatric pharmacovigilance include paediatric signal detection and signal evaluation. Both require an understanding of the paediatric safety specification, risk minimisation and paediatric clinical practice. Paediatric pharmacovigilance is challenging because, compared to adults, the absolute number of children treated with medications is smaller and due to developmental changes, the paediatric population is more heterogeneous.

\subsection{1 | Paediatric signal detection}

Paediatric signal detection takes into consideration the current paediatric safety specification of the drug and continuously monitors all available safety data for signals which might flag new risks or a change in risk factors, severity or outcome of identified risks. Where possible, paediatric clinical trial safety data should be pooled. For screening large datasets, complex statistical methods (whether frequentist or
Bayesian) are commonly used. ${ }^{105,109,141,142}$ Signals for paediatric risks may originate, for example, from health authority or pharmaceutical industry safety databases, clinical trials, observational studies, registries, non-clinical studies, PK/PD studies or the literature. ${ }^{18,103,109,141}$ For further details, see Section 2.4.3.

\subsection{2 | Paediatric signal evaluation}

Paediatric signal evaluation considers how ADRs present in children and how childhood development may modify them. It is informed by an understanding of childhood diseases, their comorbidities, common co-medications and the challenges of diagnosing and treating children. This includes an understanding of the developmental aspects influencing the assessment and therapy of paediatric diseases. The evaluation of a paediatric signal includes all available data in order to assess causality. It also determines whether additional data is required for a full assessment and proposes age-appropriate risk minimisation measures. Supporting Information Table S2 provides examples of questions for the assessment of causality of integrated paediatric safety data (clinical and non-clinical) based on the Bradford Hill points to consider. ${ }^{63,64,82,84}$ This is followed by an evaluation of the degree of certainty of a causal relationship using the WHO Uppsala Monitoring Centre (WHO-UMC) criteria. ${ }^{142}$ Supporting Information Table S7 provides hypothetical examples of the degree of certainty for a paediatric causality assessment. Paediatric pharmacoepidemiology studies are important in further characterising a paediatric risk by, for example, identifying risk factors, frequency, severity, outcome and for hypothesis testing. ${ }^{143-145}$ Further details on paediatric pharmacoepidemiology in the context of drug safety are provided in Section 2.5.3. A list of frequently used terms in pharmacovigilance and what they stand for is provided in Table S8 in the Supporting Information.

\section{3 | SUMMARY}

Paediatric pharmacovigilance and drug safety are facing a number of challenges which should be addressed in a collaborative manner by society as a whole as well as relevant key players. For example, pharmaceutical industry and regulatory authorities, with the support of academic researchers, may consider addressing the lack of paediatric formulations and age-group-specific PK and PD data for patentprotected as well as off-patent medicines regardless of their labelling status (i.e., off-label/unlicensed).

The functionality of EHRs, reimbursement records and safety databases should be updated, including databasing and coding processes and data extraction, to suit the needs of paediatric patients. This should include the option of linking to the health records of the parents and siblings where indicated. Standardised capture of paediatric data using age-group-specific tools (e.g., currently being prepared by the Clinical Data Interchange Standards Consortium [CDISC]) should be implemented for all paediatric trials irrespective of the sponsor and be a criterion for ethics and regulatory approval. This 
should be supplemented by data transparency and data sharing among researchers.

Public funding should be made available to address the lack of safety data in children, including long-term risks for off-patent, offlabel and unlicensed medicines prescribed to children.

Paediatric networks have already started to address the lack of population-based, validated references ranges for laboratory test and vital signs, outcomes and safety endpoints. Similarly, more standardised diagnostic criteria and treatment protocols are needed, taking into consideration local differences in the availability of diagnostics and treatment options. There is still a lot left to do and a coordinated effort may be helpful.

Establishing an open-source evidence-based paediatric formulary, available in multiple languages, and updated as needed, would go a long way in reducing dose-related toxicities and lack of efficacy in children. It could include a section for parents, nurses and children. Additional chapters may include information on how medications can be adapted to low-income settings and best practices for avoiding medication errors. This would require a collaborative effort of paediatricians, paediatric pharmacologists, drug safety paediatricians and paediatric pharmacists around the globe and should be funded as an independent body.

Learned societies, patient organisations and universities may consider providing educational material for parents, children and health care professionals on the recognition of adverse drug reactions in children, the importance of reporting and how to report.

The worldwide shortage of paediatric drug safety physicians and pharmacologists should be urgently addressed by universities and institutions funding higher education. In addition, the challenge of access to paediatric drug safety expertise for countries and regions where there is no or only limited expertise might be addressed by paediatric networks.

In conclusion, paediatric pharmacovigilance is based on the paediatric safety specification and supported by risk minimisation activities adapted to children and their caregivers. It is a continuous, worldwide, multidisciplinary effort throughout the life cycle of pharmaceutical products administered to children, regardless of the local licensing status. It requires an understanding of how ADRs present in children and the challenges of diagnosing and treating paediatric diseases.

\section{ACKNOWLEDGEMENT}

conect4children has received funding from the Innovative Medicines Initiative 2 Joint Undertaking under grant agreement No. 777389. The Joint Undertaking receives support from the European Union's Horizon 2020 research and innovation program and EFPIA.

\section{COMPETING INTERESTS}

B.A. has worked for GlaxoSmithKline and holds company shares. She has also worked for Novartis. The work for the present article is not related to these previous employments. T.B. served in an advisory or consultancy role for ADHS digital, Infectopharm, Lundbeck, Medice, Neurim Pharmaceuticals, Oberberg $\mathrm{GmbH}$, Roche and Takeda. He received conference support or speaker's fee by Medice and Takeda.
He received royalties from Hogrefe, Kohlhammer, CIP Medien, Oxford University Press; the present work is unrelated to these relationships. S.D. works as a paid consultant to the pharmaceutical industry. I.W. reports grants from Research Grant Council Hong Kong; personal fees from Medice; and grants and personal fees from Janssen, outside the submitted work. All other authors declared not having any conflict of interest.

\section{CONTRIBUTORS}

B.A., L.E.K., J.M.K. and I.W. wrote the article. I.W. developed the initial structure of the article. B.A. coordinated the writing of the article and created the tables and figures. All authors reviewed the article and agreed on the final version.

\section{ORCID}

Beate Aurich (D) https://orcid.org/0000-0002-8830-023X Dina Apele-Freimane (D) https://orcid.org/0000-0002-4666-4115 Tobias Banaschewski (D) https://orcid.org/0000-0003-4595-1144 Laurent Chouchana (D) https://orcid.org/0000-0002-9626-3571 Lauren E. Kelly (iD https://orcid.org/0000-0001-7567-0816 Jenny M. Kindblom (D) https://orcid.org/0000-0001-8437-0639 Antje Neubert (D) https://orcid.org/0000-0001-6575-1452

\section{REFERENCES}

1. World Health Organisation. Pharmacovigilance. 2018. https://www. who.int/medicines/areas/quality_safety/safety_efficacy/pharmvigi/ en/. Accessed August 11, 2020.

2. Council for International Organizations of Medical Sciences. Practical aspects of signal detection in pharmacovigilance - Report of CIOMS Working group VIII. Geneva 2010. https://cioms.ch/working_ groups/working-group-viii/. Accessed August 28, 2020.

3. European Medicines Agency. Guidelines on Good Pharmacovigilance Practices (GVP)-Introductory Cover Note, Last Updated with Chapter P.III on Pharmacovigilance for the Use of Medicines by Pregnant and Breastfeeding Women. 2019. https://www.ema. europa.eu/en/documents/regulatory-procedural-guideline/ guidelines-good-pharmacovigilance-practices-gvp-introductorycover-note-last-updated-chapter-piii_en.pdf. Accessed August 17, 2020.

4. European Medicines Agency, The European Network of Centres for Pharmacoepidemiology and Pharmacovigilance. Guide on Methodological Standards in Pharmacoepidemiology (Revision 8), EMA/95098/2010 Rev.8, 2010. http://www.encepp.eu/standards_ and_guidances/documents/GuideMethodRev8.pdf. Accessed August 3, 2020.

5. Choonara I, Rieder M. Drug toxicity and adverse drug reactions in children-a brief historical review. Paediatr Perinatal Drug Ther. 2002; 5(1):12-18. https://doi.org/10.1185/146300902322125109

6. Borchers AT, Hagie F, Keen CL, Gershwin ME. The history and contemporary challenges of the US Food and Drug Administration. Clin Ther. 2007;29(1):1-16. https://doi.org/10.1016/j.clinthera.2007. 01.006

7. Kearns GL, Abdel-Rahman SM, Alander SW, Blowey DL, Leeder JS, Kauffman RE. Developmental pharmacology-drug disposition, action, and therapy in infants and children. N Engl J Med. 2003; 349(12):1157-1167. https://doi.org/10.1056/NEJMra035092

8. Greene JA, Podolsky SH. Reform, regulation, and pharmaceuticalsthe Kefauver-Harris Amendments at 50. N Engl J Med. 2012;367(16): 1481-1483. https://doi.org/10.1056/NEJMp1210007 
9. Shirkey H. Therapeutic orphans. J Pediatr. 1968;72(1):119-120 https://doi.org/10.1016/s0022-3476(68)80414-7

10. Elzagallaai AA, Greff M, Rieder MJ. Adverse drug reactions in children: the double-edged sword of therapeutics. Clin Pharmacol Ther. 2017;101(6):725-735. https://doi.org/10.1002/cpt.677

11. Wimmer S, Neubert A, Rascher W. The safety of drug therapy in children. Dtsch Arztebl Int. 2015;112(46):781-787. https://doi.org/ 10.3238/arztebl.2015.0781

12. European Parliament, European Council. Regulation (EC) No 1901/2006 of the European Parliament and of the Council of 12 December 2006 on medicinal products for paediatric use and amending Regulation (EEC) No 1768/92, Directive2001/20/EC, Directive 2001/83/EC and Regulation (EC) No 726/2004. Official Journal of the European Union, 27.12.2006; L378/1. https://ec. europa.eu/health//sites/health/files/files/eudralex/vol-1/reg_ 2006_1901/reg_2006_1901_en.pdf. Accessed September 28, 2020.

13. Elie V, Leroux S, Kaguelidou F, Jacqz-Aigrain E. Drug evaluation in children 10 years after the European pediatric regulation: current challenges and perspectives. Thérapie. 2018;73(2):113-117. https:// doi.org/10.1016/j.therap.2017.11.006

14. European Medicines Agency. Paediatric investigation plans: Templates, forms and submission dates. https://www.ema.europa.eu/ en/human-regulatory/research-development/paediatric-medicines/ paediatric-investigation-plans/paediatric-investigation-planstemplates-forms-submission-dates. Accessed September 5, 2020.

15. Toma M, Felisi M, Bonifazi D, et al. The Paediatric Regulation-is it time for reform? Front Med (Lausanne). 2021;8:593281. https://doi. org/10.3389/fmed.2021.593281

16. Bhatnagar M, Sheehan S, Sharma I, et al. Prospect of direct benefit in pediatric trials: practical challenges and potential solutions. Pediatrics. 2021;147(5):e2020049602. https://doi.org/10.1542/peds. 2020-049602

17. European Medicines Agency. 10-year Report to the European Commission: General report on the experience acquired as a result of the application of the Paediatric Regulation (EMA/231225/2015). 2012.

18. European Medicines Agency. Guideline on Good Pharmacovigilance Practices (GVP) Product - or Population-Specific Considerations IV: Paediatric Population. 2018. https://www.ema.europa.eu/en/ documents/scientific-guideline/guideline-good-pharmacovigilancepractices-gvp-product-population-specific-considerations-iv_en-0. pdf. Accessed August 17, 2020.

19. European Medicines Agency. EudraVigilance: electronic reporting. $2020 . \quad$ https://www.ema.europa.eu/en/human-regulatory/ researchdevelopment/pharmacovigilance/eudravigilance/ eudravigilance-electronic-reporting. Accessed August 20, 2020.

20. US Food and Drug Administration. FDA Adverse Event Reporting System Public Dashboard. 2020. https://www.fda.gov/drugs/ questions-and-answers-fdas-adverse-event-reporting-systemfaers/ fda-adverse-event-reporting-system-faers-public-dashboard. Accessed September 3, 2020.

21. Uppsala Monitoring Centre. VigiBase: signalling harm and pointing to safer use. https://www.who-umc.org/vigibase/vigibase/vigibasesignalling-harm-and-pointing-to-safer-use/. Accessed August 24, 2020.

22. Aagaard L, Strandell J, Melskens L, Petersen PS, Holme HE. Global patterns of adverse drug reactions over a decade: analyses of spontaneous reports to VigiBase ${ }^{\mathrm{TM}}$. Drug Saf. 2012;35(12):1171-1182. https://doi.org/10.1007/BF03262002

23. Star K, Norén GN, Nordin K, Edwards IR. Suspected adverse drug reactions reported for children worldwide: an exploratory study using VigiBase. Drug Saf. 2011;34(5):415-428. https://doi.org/10. 2165/11587540-000000000-00000

24. Cummings ED, Kong EL, Edens MA. Gray Baby Syndrome. In: StatPearls [Internet]. Treasure Island, FL: StatPearls Publishing;
2021. https://www.ncbi.nlm.nih.gov/books/NBK448133/. Updated July 26, 2021. Accessed November 3, 2021.

25. Bellis JR, Kirkham JJ, Nunn AJ, Pirmohamed M. Adverse drug reactions and off-label and unlicensed medicines in children: a prospective cohort study of unplanned admissions to a paediatric hospital. Br J Clin Pharmacol. 2014;77(3):545-553. https://doi.org/10.1111/ bcp.12222

26. Metsvaht T, Nellis G, Varendi H, et al. High variability in the dosing of commonly used antibiotics revealed by a Europe-wide point prevalence study: implications for research and dissemination. BMC Pediatr. 2015;15(1):41-51. https://doi.org/10.1186/s12887-0150359-y

27. Cavell GF, Mandaliya D. Magnitude of error: a review of wrong dose medication incidents reported to a UK hospital voluntary incident reporting system. Eur J Hosp Pharm. 2021;28(5):260-265. https:// doi.org/10.1136/ejhpharm-2019-001987

28. Ho SS, McLachlan AJ, Chen TF, Hibbs DE, Fois RA. Relationships between pharmacovigilance, molecular, structural, and pathway data: revealing mechanisms for immune-mediated drug-induced liver injury. CPT Pharmacometrics Syst Pharmacol. 2015;4(7):426-441. https://doi.org/10.1002/psp4.56

29. Bellanti F, Della Pasqua O. Modelling and simulation as research tools in paediatric drug development. Eur J Clin Pharmacol. 2011; (Suppl 1):75-86. https://doi.org/10.1007/s00228-010-0974-3

30. Sutherland A, Ashcroft DM, Phipps DL. Exploring the human factors of prescribing errors in paediatric intensive care units. Arch Dis Child. 2019;104(6):588-595. https://doi.org/10.1136/archdischild-2018315981

31. Brinkman DJ, Tichelaar J, Okorie M, et al. Pharmacology and therapeutics education in the European Union needs harmonization and modernization: a cross-sectional survey among 185 medical schools in 27 countries. Clin Pharmacol Ther. 2017;102(5):815-822. https:// doi.org/10.1002/cpt.682

32. Valeur KS, Holst H, Allegaert K. Excipients in neonatal medicinal products: never prescribed, commonly administered. Pharmaceut Med. 2018;32(4):251-258. https://doi.org/10.1007/s40290-0180243-9

33. US Food and Drug Administration. FDA Drug Safety Communication: Serious health problems seen in premature babies given Kaletra (lopinavir/ritonavir) oral solution. https://www.fda.gov/drugs/drugsafety-and-availability/fda-drug-safety-communication-serioushealth-problems-seen-premature-babies-given-kaletra. Published August 4, 2017. Accessed September 23, 2020.

34. Stevens JC, Marsh SA, Zaya MJ, et al. Developmental changes in human liver CYP2D6 expression. Drug Metab Dispos. 2008;36(8): 1587-1593. https://doi.org/10.1124/dmd.108.021873

35. Wildenbeest JG, van der Schee MP, Hashimoto S, et al. Prevalence of rhinoviruses in young children of an unselected birth cohort from the Netherlands. Clin Microbiol Infect. 2016;(8):736.e9-736.e15. https://doi.org/10.1016/j.cmi.2016.05.022

36. Thompson DF, Ramos CL. Antibiotic-induced rash in patients with infectious mononucleosis. Ann Pharmacother. 2017;51(2):154-162. https://doi.org/10.1177/1060028016669525

37. Roujeau JC. Immune mechanisms in drug allergy. Allergol Int. 2006; 55(1):27-33. https://doi.org/10.2332/allergolint.55.27

38. Chow EK, Castrillo A, Shahangian A, et al. A role for IRF3-dependent RXRalpha repression in hepatotoxicity associated with viral infections. J Exp Med. 2006;203(12):2589-2602. https://doi.org/10 1084/jem.20060929

39. Gupta-Malhotra M, Banker A, Shete S, et al. Essential hypertension vs. secondary hypertension among children. Am J Hypertens. 2015, 28(1):73-80. https://doi.org/10.1093/ajh/hpu083

40. Tolaymat A, Nayak A, Geyer JD, Geyer SK, Carney PR. Diagnosis and management of childhood epilepsy. Curr Probl Pediatr Adolesc 
Health Care. 2015;45(1):3-17. https://doi.org/10.1016/j.cppeds. 2014.12.002

41. Búdi T, Tóth K, Nagy A, et al. Clinical significance of CYP2C9-status guided valproic acid therapy in children. Epilepsia. 2015;56(6):849855. https://doi.org/10.1111/epi.13011

42. Akhlaghi $F$, Matson KL, Mohammadpour AH, Kelly M, Karimani A. Clinical pharmacokinetics and pharmacodynamics of antihyperglycemic medications in children and adolescents with type 2 diabetes mellitus. Clin Pharmacokinet. 2017;56(6):561-571. https://doi.org/10.1007/s40262-016-0472-6

43. Eaton DK, Kann L, Kinchen S, et al. Youth risk behavior surveillance-United States, 2011. MMWR Surveill Summ. 2012; 61(4):1-162.

44. Song M, Omar HA. Discovering the complexities of adolescent compliance to treatment. Int J Adolesc Med Health. 2009;21(1):3-8. https://doi.org/10.1515/ijamh.2009.21.1.3

45. Nicholas JM, Ridsdale L, Richardson MP, Ashworth M, Gulliford MC. Trends in antiepileptic drug utilisation in UK primary care 19932008: cohort study using the General Practice Research Database. Seizure. 2012;21(6):466-470. https://doi.org/10.1016/j.seizure. 2012.04.014

46. Neubert A, Verhamme K, Murray ML, et al. The prescribing of analgesics and non-steroidal anti-inflammatory drugs in paediatric primary care in the UK, Italy and the Netherlands. Pharmacol Res. 2010;62(3):243-248. https://doi.org/10.1016/j.phrs.2010. 04.006

47. Sadowska M, Sarecka-Hujar B, Kopyta I. Cerebral palsy: current opinions on definition, epidemiology, risk factors, classification and treatment options. Neuropsychiatr Dis Treat. 2020;16:1505-1518. https://doi.org/10.2147/NDT.S235165

48. Hom M, Sriprasert I, Ihenacho U, et al. Systematic review and metaanalysis of testicular germ cell tumors following in utero exposure to diethylstilbestrol. JNCl Cancer Spectr. 2019;3(3):pkz045. https://doi. org/10.1093/jncics/pkz045

49. Titus L, Hatch EE, Drake KM, et al. Reproductive and hormone-related outcomes in women whose mothers were exposed in utero to diethylstilbestrol (DES): a report from the US National Cancer Institute DES Third Generation Study. Reprod Toxicol. 2019;84:32-38. https://doi.org/10.1016/j.reprotox.2018. 12.008

50. Balsells M, García-Patterson A, Gich I, Corcoy R. Major congenital malformations in women with gestational diabetes mellitus: a systematic review and meta-analysis. Diabetes Metab Res Rev. 2012; 28(3):252-257.

51. Meador KJ, Baker GA, Browning $\mathrm{N}$, et al. Fetal antiepileptic drug exposure and cognitive outcomes at age 6 years (NEAD study): a prospective observational study. Lancet Neurol. 2013;12(3): 244-252.

52. Spencer L, Bubner T, Bain E, Middleton P. Screening and subsequent management for thyroid dysfunction pre-pregnancy and during pregnancy for improving maternal and infant health. Cochrane Database Syst Rev. 2015;9:CD011263. https://doi.org/10.1002/ 14651858.CD011263.pub2

53. Matics TJ, Khan N, Jani P, Kane JM. The Fragility Index in a cohort of pediatric randomized controlled trials. J Clin Med. 2017; 6(8):79-87. https://doi.org/10.3390/jcm6080079

54. Bridges AJ, Holler KA. How many is enough? Determining optimal sample sizes for normative studies in pediatric neuropsychology. Child Neuropsychol. 2007;13(6):528-538. https://doi.org/10.1080/ 09297040701233875

55. Hopstadius J, Norén GN, Bate A, Edwards IR. Impact of stratification on adverse drug reaction surveillance. Drug Saf. 2008; 31(11):1035-1048. https://doi.org/10.2165/00002018-2008311 10-00008
56. Fenton TR, Chan HT, Madhu A, et al. Preterm infant growth velocity calculations: a systematic review. Pediatrics. 2017;139(3): e20162045. https://doi.org/10.1542/peds.2016-2045

57. Adams M, Bassler D. Practice variations and rates of late onset sepsis and necrotizing enterocolitis in very preterm born infants, a review. Transl Pediatr. 2019;8(3):212-226. https://doi.org/10. 21037/tp.2019.07.02

58. Adeli K, Higgins V, Trajcevski K, White-Al HN. The Canadian laboratory initiative on pediatric reference intervals: a CALIPER white paper [published correction appears in Crit Rev Clin Lab Sci. 2020; 57(2):145]. Crit Rev Clin Lab Sci. 2017;54(6):358-413. https://doi. org/10.1080/10408363.2017.1379945

59. Lucile Packard Children's Hospital Standford, Standford Children's Health. Age-appropriate speech and language milestones. 2020. https://www.stanfordchildrens.org/en/topic/default?id=ageappropriate-speech-and-language-milestones-90-P02170. Accessed September 10, 2020.

60. European Medicines Agency. Guidance on the Format of the Risk Management Plan (RMP) in the EU - in Integrated Format, EMA/164014/2018 Rev.2.0.1 Accompanying GVP Module V Rev.2, Human Medicines Evaluation. https://www.ema.europa.eu/en/ documents/regulatory-procedural-guideline/guidance-format-riskmanagement-plan-rmp-eu-integrated-format-rev-201_en.pdf. Published October 31, 2018. Accessed August 17, 2020.

61. International Council for Harmonisation of Technical Requirements for Pharmaceuticals for Human Use (ICH). ICH Harmonised Guidelines - Integrated Addendum to ICH E6 (R1): Guidelines for Good Clinical Practice E6 5R2). Current Step 4 version dated 9 November 2016. https://database.ich.org/sites/default/ files/E6_R2_Addendum.pdf. Accessed November 14, 2020.

62. International Council for Harmonisation of Technical Requirements for Pharmaceuticals for Human Use (ICH). ICH Harmonised Guideline - Addendum to ICH E11: Clinical investigation of medicinal products in the pediatric population E11 (R1), Final Version. Adopted on 18 August 2017. https://database.ich.org/ sites/default/files/E11_R1_Addendum.pdf. Accessed November 14, 2010.

63. Fedak KM, Bernal A, Capshaw ZA, Gross S. Applying the Bradford Hill criteria in the 21st century: how data integration has changed causal inference in molecular epidemiology. Emerg Themes Epidemiol. 2015;12(1):14-23. https://doi.org/10.1186/s12982-0150037-4

64. Perrio M, Voss S, Shakir SA. Application of the Bradford Hill criteria to assess the causality of cisapride-induced arrhythmia: a model for assessing causal association in pharmacovigilance. Drug Saf. 2007; 30(4):333-346. https://doi.org/10.2165/00002018-20073004000006

65. US Department of Health and Human Services, Food and Drug Administration, Center for Drug Evaluation and Research, Center for Biologics Evaluation and Research. Guidance for Industry DrugInduced Liver Injury: Premarketing Clinical Evaluation. July 2009. https://www.fda.gov/media/116737/download. Accessed August 14, 2020.

66. Hartman SJF, Orriëns LB, Zwaag SM, Poel T, de Hoop M, de Wildt SN. External validation of model based dosing guidelines for vancomycin, gentamicin, and tobramycin in critically ill neonates and children: a pragmatic two-center study. Paediatr Drugs. 2020;22(4):433-444. https://doi.org/10.1007/s40272-02000400-8

67. Karnes JH, Rettie AE, Somogyi AA, et al. Clinical Pharmaco-genetics Implementation Consortium (CPIC) guideline for CYP2C9 and HLA-B genotypes and phenytoin dosing: 2020 update. Clin Pharmacol Ther. 2021;109(2):302-309. https://doi.org/10.1002/cpt. 2008 
68. Smyth RL. Lessons from normal heart and respiratory rates in children. Lancet. 2011;377(9770):974-975. https://doi.org/10.1016/ S0140-6736(11)60102-5

69. Hagedoorn NN, Zachariasse JM, Moll HA. A comparison of clinical paediatric guidelines for hypotension with population-based lower centiles: a systematic review. Crit Care. 2019;23(1):380-390. https://doi.org/10.1186/s13054-019-2653-9

70. European Medicines Agency, Committee for Medicinal Products for Human Use. Guideline on key aspects for the use of pharmacogenomics in the pharmacovigilance of medicinal products. EMA/CHMP/281371/2013, 24 September 2015. https://www.ema. europa.eu/en/documents/scientific-guideline/guideline-keyaspects-use-pharmacogenomics-pharmacovigilance-medicinalproducts_en.pdf. Accessed August 5, 2020.

71. European Medicines Agency. Designated Medical Events. 2020. https://www.ema.europa.eu/en/human-regulatory/postauthorisation/pharmacovigilance/signal-management\#designatedmedical-events-section. Accessed September 3, 2020.

72. Aurich B, Jacqz-Aigrain E. Safety data collection and risk management in paediatric clinical trials: literature review of points to consider during protocol development. September 2020; ICPE. https:// www.eventscribe.com/2020/ICPEAllAccess/fsPopup.asp?efp= UkZVWFVDT04xMjMxOA\&PosterID =295921\&rnd $=0.793508 \&$ mode $=$ posterinfo. Accessed October 3, 2020.

73. Flanagan SM, Greenfield S, Coad J, Neilson S. An exploration of the data collection methods utilised with children, teenagers and young people (CTYPs). BMC Res Notes. 2015;8(1):61-75. https://doi.org/ 10.1186/s13104-015-1018-y

74. European Medicines Agency; Committee for Medicinal Products for Human Use; Paediatric Committee. Guideline on the Investigation of Medicinal Products in the Term and Preterm Neonate, Doc. Ref. EMEA/536810/2008. European Medicines Agency June 25, 2009. https://www.ema.europa.eu/en/documents/scientific-guideline/ guideline-investigation-medicinal-products-term-preterm-neonatefirst-version_en.pdf. Accessed July 23, 2020.

75. Howie SR. Blood sample volumes in child health research: review of safe limits. Bull World Health Organ. 2011;89(1):46-53. https://doi. org/10.2471/BLT.10.080010

76. World Health Organization. WHO Guidelines on Drawing Blood: Best Practices in Phlebotomy. Geneva, 2010. https://www.euro. who.int/__data/assets/pdf_file/0005/268790/WHO-guidelines-ondrawing-blood-best-practices-in-phlebotomy-Eng.pdf?ua=1. Accessed August 28, 2020.

77. Bird C, Michie C. Measuring blood pressure in children. BMJ. 2008; 336(7657):1321. https://doi.org/10.1136/bmj.a150

78. Zakirova-Engstrand R, Hirvikoski T, Westling Allodi M, RollPettersson L. Culturally diverse families of young children with ASD in Sweden: parental explanatory models. PLoS One. 2020;15(7): e0236329. https://doi.org/10.1371/journal.pone.0236329

79. Rosenbaum M, Dineen R, Schmitz K, Stoll J, Hsu M, Hodges PD. Interpreters' perceptions of culture bumps in genetic counseling. J Genet Couns. 2020;29(3):352-364. https://doi.org/10.1002/jgc4. 1246

80. International Council for Harmonisation of Technical Requirements for Pharmaceuticals for Human use. Medical Dictionary for Regulatory Activities (MedDRA)-MedDRA ${ }^{\circledR}$ Term selection: Points to consider-Endorsed Guide for MedDRA Users Release 4.19 Based on MedDRA Version 23.0. 1 March 2020. https://admin.new. meddra.org/sites/default/files/guidance/file/000401_termselptc_ r4_19_mar2020_13.pdf. Accessed September 30, 2020.

81. European Medicines Agency. Guideline on good pharmacovigilance practices (GVP) Module VI - Collection, management and submission of reports of suspected adverse reactions to medicinal products (Rev 2). 28 July 2017, EMA/873138/2011 Rev 2*. https://www. ema.europa.eu/en/documents/regulatory-procedural-guideline/ guideline-good-pharmacovigilance-practices-gvp-module-vi-collec tion-management-submission-reports_en.pdf. Accessed September 14, 2020.

82. Council for International Organizations of Medical Sciences Working Group. Management of Safety Information from Clinical Trials: Report of CIOMS Working Group VI; 2005. https://cioms.ch/wpcontent/uploads/2017/01/Mgment_Safety_Info.pdf. Accessed January 23, 2020.

83. International Council for Harmonisation of Technical Requirements for Pharmaceuticals for Human use (ICH). Maintenance of the $\mathrm{ICH}$ Guideline on Clinical Safety Data Management: Data elements for transmission of individual case safety reports E2B (R2), Step 4. February 5, 2001. https://admin.ich.org/sites/default/files/inlinefiles/E2B_R2_Guideline.pdf. Accessed December 1, 2020.

84. Bradford Hill A. The environment and disease: association or causation? J R Soc Med. 2015;108(1):32-37. https://doi.org/10.1177/ 0141076814562718

85. US Department of Health and Human Services. Common Terminology Criteria for Adverse Events (CTCAE) Version 5.0. https://ctep. cancer.gov/protocolDevelopment/electronic_applications/docs/ CTCAE_v5_Quick_Reference_5x7.pdf. Published November 27, 2017. Accessed August 10, 2020.

86. Division of AIDS, National Institute of Allergy and Infectious Diseases, National Institutes of Health, US Department of Health and Human Services. Division of AIDS (DAIDS) Table for Grading the Severity of Adult and Pediatric Adverse Events, corrected version 2.1. July 2017. https://rsc.niaid.nih.gov/sites/default/files/ daidsgradingcorrectedv21.pdf. Accessed August 16, 2020.

87. Salaets T, Turner MA, Short M, et al. Development of a neonatal adverse event severity scale through a Delphi consensus approach. Arch Dis Child. 2019;104(12):1167-1173. https://doi.org/10.1136/ archdischild-2019-317399

88. Richesson RL, Smith SB, Malloy J, Krischer JP. Achieving standardized medication data in clinical research studies: two approaches and applications for implementing RxNorm. J Med Syst. 2010;34(4): 651-657. https://doi.org/10.1007/s10916-009-9278-5

89. Maddox J \& Decker C RA01 Standardizing FDA Data to Improve Success in Pediatric Drug Development-Case Study: Harmonizing Hypertensive Pediatric Data across Sponsors using SAS $^{\circledR}$ and the CDISC Model. Pharmaceutical Users Software Exchange (PHUSE) Conference 8-10 October 2007, Lisbon, Portugal. https://www. lexjansen.com/phuse/2007/ra/RA01.pdf. Accessed August $29,2020$.

90. Clinical Data Interchange Standards Consortium (CDISC). Clinical Data Interchange Standards. https://www.cdisc.org/system/files/ members/standard/foundational/cdash/CDASHIG\%20v2.1.pdf. Accessed September 15, 2020.

91. Barker CIS, Standing JF, Kelly LE, et al. Pharmacokinetic studies in children: recommendations for practice and research. Arch Dis Child. 2018;103(7):695-702. https://doi.org/10.1136/archdischild-2017314506

92. International Council for Harmonisation of Technical Requirements for Pharmaceuticals for Human use. Medical Dictionary for Regulatory Activities (MedDRA)-Introductory Guide for Standardised MedDRAQueries (SMQs) Version 23.1. https://admin.new.meddra. org/sites/default/files/guidance/file/SMQ_intguide_23_1_English. pdf. Published September 2020. Accessed October 2, 2020.

93. Breder CD. Informative graphing of continuous safety variables relative to normal reference limits. BMC Med Res Methodol. 2018;18(1): 40-48. https://doi.org/10.1186/s12874-018-0504-z

94. Crowe BJ, Xia HA, Berlin JA, et al. Recommendations for safety planning, data collection, evaluation and reporting during drug, biologic and vaccine development: a report of the safety planning, evaluation, and reporting team. Clin Trials. 2009;6(5):430-440. https:// doi.org/10.1177/1740774509344101 
95. Gebski V, Garès V, Gibbs E, Byth K. Data maturity and follow-up in time-to-event analyses. Int J Epidemiol. 2018;47(3):850-859. https:// doi.org/10.1093/ije/dyy013

96. Phillips R, Hazell L, Sauzet O, Cornelius V. Analysis and reporting of adverse events in randomised controlled trials: a review. BMJ Open. 2019;9(2):e024537. https://doi.org/10.1136/bmjopen-2018024537

97. Phillips R, Cornelius V. Understanding current practice, identifying barriers and exploring priorities for adverse event analysis in randomised controlled trials: an online, cross-sectional survey of statisticians from academia and industry. BMJ Open. 2020;10(6):e036875. https://doi.org/10.1136/bmjopen-2020-036875

98. Council for International Organizations of Medical Sciences. Guidelines for preparing core clinical safety information on drugs-Reports of CIOMS Working Group III. 1995. https://cioms.ch/wp-content/ uploads/2018/03/WG3_Guidelines-for-Preparing-Core-ClinicalSafety-Information-on-Drugs.pdf. Accessed August 28, 2020.

99. European Commission. A guideline on summary of product characteristics (SmPC), Revision 2. September 2009. https://ec.europa.eu/ health//sites/health/files/files/eudralex/vol-2/c/smpc_guideline_ rev2_en.pdf. Accessed August 21, 2020.

100. Dittrich ATM, Draaisma JMT, van Puijenbroek EP, Loo DMWMT. Analysis of reporting adverse drug reactions in paediatric patients in a university hospital in the Netherlands. Paediatr Drugs. 2020;22(4): 425-432. https://doi.org/10.1007/s40272-020-00405-3

101. Fadini GP, Sarangdhar M, Avogaro A. Pharmacovigilance evaluation of the association between DPP-4 inhibitors and heart failure: stimulated reporting and moderation by drug interactions. Diabetes Ther. 2018;9(2):851-861. https://doi.org/10.1007/s13300018-0408-2

102. Impicciatore $\mathrm{P}$, lato V, Sevoz V, Mucci M. Quality of published case reports on adverse drug reactions in children. Arch Dis Child. 2012; 97(9):853.

103. Barton C, Hawcutt DB. When to report adverse drug reactions in children? Arch Dis Child. 2015;100(7):682-683. https://doi.org/10. 1136/archdischild-2014-307906

104. Medicines and Healthcare products Regulatory Agency (MHRA). Specific areas of interest for reporting suspected adverse drug reactions. 2020. Available at: https://assets.publishing.service.gov.uk/ government/uploads/system/uploads/attachment_data/file/ 403078/Specific_areas_of_interest_for_adverse_drug_reaction_ reporting.pdf. Accessed August 10, 2020.

105. Caster O, Juhlin K, Watson S, Norén GN. Improved statistical signal detection in pharmacovigilance by combining multiple strength-ofevidence aspects in vigiRank. Drug Saf. 2014;37(8):617-628. https://doi.org/10.1007/s40264-014-02045

106. Kelly W, Arellano F, Barnes J, et al. Guidelines for submitting adverse event reports for publication. Thérapie. 2009;64(4):289294. https://doi.org/10.2515/therapie/2009041

107. World Health Organisation. Essential medicines and health products-Defined Daily Dose (DDD). 2020. https://www.who.int/ medicines/regulation/medicines-safety/toolkit_ddd/en/. Accessed August 14, 2020.

108. Cliff-Eribo KO, Sammons H, Choonara I. Systematic review of paediatric studies of adverse drug reactions from pharmacovigilance databases. Expert Opin Drug Saf. 2016;15(10):1321-1328. https://doi. org/10.1080/14740338.2016.1221921

109. Aurich-Barrera B, Wilton L, Brown D, Shakir S. Paediatric postmarketing pharmacovigilance using prescription-event monitoring: comparison of the adverse event profiles of lamotrigine prescribed to children and adults in England. Drug Saf. 2010;33(9):751-763. https://doi.org/10.2165/11536830-000000000-00000

110. Schulz KF, Grimes DA. Case-control studies: research in reverse. Lancet. 2002;359(9304):431-434. https://doi.org/10.1016/S01406736(02)07605-5
111. Grenier D, Lynn R, Zurynski Y. Public health impacts of the International Network of Paediatric Surveillance Units. Paediatr Child Health. 2009;14(8):499-500.

112. Lynn RM. The International Network of Paediatric Surveillance Units (INoPSU)-increasing European contribution to the surveillance of rare paediatric disease. Euro Surveill. 2002;6(2)pii=2000. https://doi. org/10.2807/esw.06.02.02000-en

113. International Association of Cancer Registries. History and aims of the Association. 2020. http://www.iacr.com.fr/index.php? option $=$ com_content\&view $=$ article\&id $=89 \&$ Itemid $=439$. Accessed September 3, 2020.

114. European Cycstic Fibrosis Society. ECSF Patient registry. 2020. https://www.ecfs.eu/ecfspr. Accessed October 3, 2020.

115. European Medicines Agency. Post-authorisation safety studies (PASS). 2020. https://www.ema.europa.eu/en/human-regulatory/ post-authorisation/pharmacovigilance/post-authorisation-safetystudies-pass-0. Accessed September 21, 2020.

116. Patel TJ, Ayub A, Irvine MA, et al. 179-LB: Characteristics of children with medication-induced diabetes (MID): a Canadian Pediatric Surveillance Program (CPSP) study. Diabetes. 2020;69(Suppl 1) 179-LB. https://doi.org/10.2337/db20-179-LB

117. Hennessy S. Use of health care databases in pharmacoepidemiology. Basic Clin Pharmacol Toxicol. 2006;98(3):311-313. https://doi.org/ 10.1111/j.1742-7843.2006.pto_368.x

118. Hall GC, Sauer B, Bourke A, Brown JS, Reynolds MW, LoCasale R. Guidelines for good database selection and use in pharmacoepidemiology research. Pharmacoepidemiol Drug Saf. 2012; 21(1):1-10. https://doi.org/10.1002/pds.2229

119. US Department of Health and Human Services, Food and Drug Administration, Center for Drug Evaluation and Research, Center for Biologics Evaluation and Research. Guidance for Industry and FDA Staff Best Practices for Conducting and Reporting Pharmacoepidemiologic Safety Studies Using Electronic Healthcare Data. May 2013. https://www.fda.gov/media/79922/download. Accessed August 22, 2020.

120. The European Network of Centres for Pharmacoepidemiology and Pharmacovigilance. Guide on Methodological Standards in Pharmacoepidemiology (Revision 8). EMA/95098/2010. http:// www.encepp.eu/standards_and_guidance. Accessed August 22, 2020.

121. The European Network of Centres for Pharmacoepidemiology and Pharmacovigilance. ENCePP Checklist for Study Protocols (Revision 4). EMA/540136/2009. Adopted by the ENCePP Steering Group on 15/10/2018. http://www.encepp.eu/standards_and_guidances/ checkListProtocols.shtml. Accessed August 22, 2020.

122. Dufendach KR, Eichenberger JA \& McPheeters ML et al. Core Functionality in Pediatric Electronic Health Records [Internet]. Report No.: 15-EHC014-EF. Rockville, MD: Agency for Healthcare Research and Quality (US); 2015. https://www.ncbi.nlm. nih. gov/books/NBK293626/pdf/Bookshelf_NBK293626.pdf. Accessed 25 September 2020.

123. McMahon AW, Wharton GT, Bonnel R, et al. Pediatric postmarketing safety systems in North America: assessment of the current status. Pharmacoepidemiol Drug Saf. 2015;24(8):785-792. https://doi.org/10.1002/pds.3813 Erratum in: Pharmacoepidemiol Drug Saf. 2016;25(1):110-111

124. Hughes D, Waddingham E, Mt-Isa S, et al. Recommendations for benefit-risk assessment methodologies and visual representations. Pharmacoepidemiol Drug Saf. 2016;25(3):251-262. https://doi.org/ 10.1002/pds.3958

125. Pharmacoepidemiological Research on Outcomes of Therapeutics by a European ConsorTium (PROTECT). Recommendations for the methodology and visualisation techniques to be used in the assessment of benefit and risk of medicines; 2013. http://www.imiprotect.eu/documents/HughesetalRecommendationsforthemetho 
dologyandvisualisationtechniquestobeusedintheassessmento.pdf. Accessed October 2, 2020.

126. Fisher LM, Martinez AS, Richmond FJ, Krieger MD, Wilkinson EP, Eisenberg LS. Assessing the benefit-risk profile for pediatric implantable auditory prostheses. Ther Innov Regul Sci. 2018;52(5):669-679. https://doi.org/10.1177/2168479017741111

127. Molloy EJ, Mader S, Modi N, Gale C. Parent, child and public involvement in child health research: core value not just an optional extra. Pediatr Res. 2019;85(1):2-3. https://doi.org/10.1038/s41390018-0245-z

128. World Medical Association. Background document Declaration of Ottawa on Child Health. 2009, Ottawa, Canada. https://www.wma. net/wp-content/uploads/2017/02/Background_Ottawa_ Declaration-Oct2009.pdf. Accessed September 10, 2020.

129. European Medicines Agency, Committee for Medicinal Products for Human Use, Paediatric Committee. Guideline on pharmaceutical development of medicines for paediatric use. EMA/CHMP/QWP/805880/2012 Rev. 2, 1 August 2013. https://www. ema.europa.eu/en/documents/scientific-guideline/guidelinepharmaceutical-development-medicines-paediatric-use_en.pdf. Accessed August 5, 2020.

130. O'Brien F, Clapham D, Krysiak K, et al. Making medicines baby size: the challenges in bridging the formulation gap in neonatal medicine. Int J Mol Sci. 2019;20(11):pii:E2688. https://doi.org/10.3390/ ijms20112688

131. Geißler C, Schulze C, Botzenhardt S, Rascher W, Neubert A. Drug utilisation and off-label use on a German neonatal intensive care unit: a retrospective cohort study and 10-year comparison. Pharmacy (Basel). 2020;8(3):E173. https://doi.org/10.3390/ pharmacy8030173

132. García-López I, Cuervas-Mons Vendrell M, Martín Romero I, de Noriega I, Benedí González J, Martino-Alba R. Off-label and unlicensed drugs in pediatric palliative care: a prospective observational study. J Pain Symptom Manage. 2020;60(5):923-932. https:// doi.org/10.1016/j.jpainsymman.2020.06.014

133. Stavroudis TA, Shore AD, Morlock L, Hicks RW, Bundy D, Miller MR. NICU medication errors: identifying a risk profile for medication errors in the neonatal intensive care unit. J Perinatol. 2010;30(7):459-468. https://doi.org/10.1038/jp.2009.186

134. Kogermann K, Lass J, Nellis G, Metsvaht T, Lutsar I. Age-appropriate formulations including pharmaceutical excipients in neonatal medicines. Curr Pharm Des. 2017;23(38):5779-5789. https://doi.org/10. 2174/1381612823666170926122613

135. Valeur KS, Hertel SA, Lundstrøm KE, Holst H. The cumulative daily tolerance levels of potentially toxic excipients ethanol and propylene glycol are commonly exceeded in neonates and infants. Basic Clin Pharmacol Toxicol. 2018;122(5):523-530. https://doi.org/10. 1111/bcpt.12950

136. Akinmboni TO, Davis NL, Falck AJ, Bearer CF, Mooney SM. Excipient exposure in very low birth weight preterm neonates. J Perinatol. 2018;38(2):169-174. https://doi.org/10.1038/jp.2017.165
137. Hsieh S, Sapkota A, Wood R, Bearer C, Kapoor S. Neonatal ethanol exposure from ethanol-based hand sanitisers in isolettes. Arch Dis Child Fetal Neonatal Ed. 2018;103(1):F55-F58. https://doi.org/10. 1136/archdischild-2016-311959

138. Food and Drug Administration. Drug safety communication: serious health problems seen in premature babies given Kaletra (lopinavir/ritonavir) oral solution. 2011. https://www.fda.gov/ drugs/drugsafety/ucm246002.htm. Accessed August 5, 2020.

139. Gupta A, Khan MA. Challenges of pediatric formulations: a FDA science perspective. Int J Pharm. 2013;457(1):346-348. https://doi. org/10.1016/j.ijpharm.2013.08.064

140. Salunke S, Tuleu C. The STEP database through the end-users eyes-USABILITY STUDY. Int J Pharm. 2015;492(1-2):316-331. https://doi.org/10.1016/j.ijpharm.2015.06.016

141. Caster O, Aoki Y, Gattepaille LM, Grundmark B. Disproportionality analysis for pharmacovigilance signal detection in small databases or subsets: recommendations for limiting false-positive associations. Drug Saf. 2020;43(5):479-487. https://doi.org/10.1007/s40264020-00911-w

142. European Medicines Agency, Inspections, Human Medicines, Pharmacovigilance and Committees Division. Screening for adverse reactions in EudraVigilance. EMA/849944/2016, 19 December 2016. https://www.ema.europa.eu/en/documents/other/screeningadverse-reactions-eudravigilance_en.pdf. Accessed September 29, 2020.

143. Man KKC, Lau WCY, Coghill D, et al. Association between methylphenidate treatment and risk of seizure: a population-based, selfcontrolled case-series study. Lancet Child Adolesc Health. 2020;4(6): 435-443. https://doi.org/10.1016/S2352-4642(20)30100-0

144. Man KKC, Coghill D, Chan EW, et al. Association of risk of suicide attempts with methylphenidate treatment. JAMA Psychiat. 2017; 74(10):1048-1055. https://doi.org/10.1001/jamapsychiatry.2017. 2183

145. Gupta K. CYP2C19 phenotype and risk of proton pump inhibitorassociated infections. Pediatrics. 2020;145(6):e20200867A. https:// doi.org/10.1542/peds.2020-0867A

\section{SUPPORTING INFORMATION}

Additional supporting information may be found in the online version of the article at the publisher's website.

How to cite this article: Aurich B, Apele-Freimane D, Banaschewski T, et al. c4c: Paediatric pharmacovigilance: Methodological considerations in research and development of medicines for children - A c4c expert group white paper. $\mathrm{Br}$ J Clin Pharmacol. 2021;1-20. doi:10.1111/bcp.15119 